\title{
Durata ed efficienza dei procedimenti penali italiani. Riflessioni e proposte alla luce delle risultanze numeriche.
}

\author{
Length and efficiency of Italian criminal proceedings. \\ Remarks and proposals in the light of numerical data.
}

\section{Nicola Pascucci ${ }^{1}$}

Università degli Studi di Urbino Carlo Bo, Urbino, Italia nicola.pascucci@uniurb.it https://orcid.org/0000-0002-3232-2042

\begin{abstract}
RıAsSUNTO: La Costituzione italiana e la Convenzione europea dei diritti dell'uomo sanciscono, benché con formulazioni diverse, la ragionevole durata del processo. Dopo aver esaminato tale principio nei suoi significati di garanzia oggettiva e soggettiva, nonché i suoi rapporti con le altre garanzie costituzionali del giusto processo, l'Autore, utilizzando i dati ufficiali sul numero e sulla durata dei procedimenti penali, analizza le principali difficoltà dell'attuale assetto legislativo nel realizzare una giustizia veloce e giusta. Alla luce della situazione concreta così delineata, si formulano alcune proposte de iure condendo.
\end{abstract}

Parole chiave: ragionevole durata del processo; giusto processo; Costituzione; CEDU.

AвSTRACT: Italian Constitution and European Convention on Human Rights provide for the reasonable length of proceedings, although they use different expressions. First of all the Author examines this principle as objective and subjective guarantee, as well as its relations with the other constitutional guarantees of fair trial. Then he analyses the main difficulties of the current legislation to realize a speedy and fair justice, by means of official data about

1 Dottore di ricerca e collaboratore di cattedra (s.s.d.: IUS/16 - Diritto processuale penale) presso l'Università degli Studi di Urbino Carlo Bo. Avvocato del Foro di Urbino. 
number and duration of criminal proceedings. In light of the practical situation, the Author formulates some reform proposals.

KEYWORDS: reasonable length of proceedings; fair trial; Constitution; ECHR.

Sommario: 1. Introduzione. La ragionevole durata del processo nella Costituzione e nella Convenzione europea dei diritti dell'uomo; 2. Il carico di lavoro della giustizia penale italiana; 3. Segue: gli uffici g.i.p.-g.u.p., i tribunali monocratici e collegiali; 4. Segue: le corti d'assise; 5. Segue: i giudici di pace; 6. Segue: le corti d'appello; 7. Segue: la Corte di cassazione; 8 . Cosa fare? Considerazioni finali e prospettive di riforma.

\section{INTRODUZIONE. LA RAGIONEVOLE DURATA DEL PROCESSO NELLA Costituzione E NELLA ConVEnZIONE EUROPEA DEI DiRITTI DELL'UOMO.}

Col d.p.r. 22 settembre 1988, n. 447, entrato in vigore il 24 ottobre 1989, il legislatore italiano adottava un nuovo codice di procedura penale ispirato al sistema accusatorio, abbandonando il modello misto tendenzialmente inquisitorio del previgente codice Rocco.

A distanza di oltre trent'anni, si coglie tuttavia una notevole disillusione. Detta percezione, talvolta amplificata dai mass media e assecondata dalla maggioranza politica di turno, ha condotto ad innumerevoli modifiche legislative, spesso in chiave repressiva e prive di visione sistematica, che hanno profondamente modificato l'iniziale fisionomia del procedimento. Le modifiche hanno praticamente inciso su ogni settore del codice, senza però, a quanto pare, ottenere risultati soddisfacenti, a dimostrazione del fatto che eventuali responsabilità di una crisi del sistema non possono ricondursi unicamente a singoli istituti ${ }^{2}$.

2 Per tale senso d'insoddisfazione e per l'impossibilità di imputare i problemi della nostra giustizia penale a particolari istituti, v. GARUTI, Giulio, Proposte per la ricostruzione sistematica del processo accusatorio: la fonte costituzionale, in Arch. pen. - Riv. web, 2017, n. 3, p. 1. 
Sono di solito percepite come problemi diffusi della giustizia penale italiana l'inefficienza processuale e la lentezza dei procedimenti ${ }^{3}$, benché la ragionevole durata del processo sia formalmente sancita dall'art. 111 comma 2 Cost. e dall'art. 6 par. 1 CEDU.

Il principio in esame è strutturato in modo differente nell'ordinamento costituzionale e in quello europeo: l'art. 111 comma 2 Cost. dispone, al secondo periodo, che «la legge (...) assicura la ragionevole durata» del processo ${ }^{4}$, mentre l'art. 6 par. 1 CEDU afferma che «ogni persona ha diritto a che la sua causa sia esaminata (...) entro un termine ragionevole da un tribunale (...), il quale sia chiamato a pronunciarsi (...) sulla fondatezza di ogni accusa penale formulata nei suoi confronti» ${ }^{5}$. Il primo pone una «"garanzia oggettiva” della giurisdizione», che si rivolge al legislatore e che gli demanda il compito di fornire gli strumenti per realizzarla; il secondo - così come l'art. 47 comma 2 Carta dei diritti fondamentali dell'Unione europea e l'art. 14 comma 3 lett. $c$ Patto internazionale sui diritti civili e politici - sancisce un diritto soggettivo direttamente azionabile dall'accusato nel singolo processo ${ }^{6}$.

3 Secondo NACAR, Barbara, I termini e la ragionevole durata del processo penale, Giappichelli, Torino, 2012, p. 74, la ragionevole durata riguarda i singoli procedimenti mentre l'efficienza concerne l'insieme delle regole astratte, processuali e organizzative, che rendono possibile una conclusione del procedimento in tempi brevi, rispettando anche gli altri corollari del giusto processo. Per una diversa accezione, TONINI, Paolo, Disciplina della prova e durata ragionevole del processo penale, in Cass. pen., 2004, p. 332, il quale, distinguendo tra efficacia ed efficienza, afferma che la prima rappresenta il livello di «raggiungimento di un obiettivo prefissato», che per il procedimento penale è l'accertamento dell'eventuale colpevolezza oltre ogni ragionevole dubbio, mentre la seconda è un rapporto proporzionato tra "mezzi" e "fine", che implica la riduzione di ogni spreco.

4 Nonostante la sua formulazione letterale, il termine va inteso in senso ampio, comprensivo anche delle indagini preliminari: FERRUA, Paolo, La ragionevole durata del processo tra Costituzione e Convenzione europea, in www. questionegiustizia.it.

5 Per la persona in stato di arresto o di detenzione, la previsione è corroborata dall'art. 5 par. 3 CEDU, secondo cui la stessa deve essere tradotta prima possibile davanti al giudice e «ha diritto di essere giudicata entro un termine ragionevole o di essere messa in libertà durante la procedura», eventualmente previa prestazione di garanzie «che assicurino la comparizione dell'interessato all'udienza».

6 GREVI, Vittorio, Il principio della «ragionevole durata» come garanzia oggettiva del «giusto processo» penale, in Cass. pen., 2003, p. 3204 ss., spec. p. 3207. 
In dottrina si è altresì prospettata una lettura alternativa dell'art. 111 comma 2 Cost., finalizzata a leggere la ragionevole durata unicamente in chiave soggettivistica, al pari di quanto prescritto dall'art. 6 par. 1 CEDU e dalle altre Carte sopranazionali. Tale interpretazione reputa viziato il concetto stesso di "garanzia oggettiva", ritenendolo radicalmente incompatibile con la tradizione liberale occidentale e frutto di una cultura inquisitoria, volta a collocare su un piano di primazia l'interesse statuale alla celere repressione dei reati rispetto alla tutela del singolo dagli abusi della pubblica autorità7. Detta impostazione, stante il riferimento della locuzione «ne assicura» ex art. 111 comma 2 Cost. al «processo»e al «contraddittorio tra le parti», attribuisce la titolarità della garanzia a coloro che assumono appunto la qualità di parte e in primis all'imputato, essendo quest'ultimo bisognoso di una più intensa tutela poiché in posizione di maggior debolezza rispetto al pubblico ministero (parte pubblica e «dominus dei tempi delle indagini»). Ad ulteriore dimostrazione di questa lettura starebbe l'art. 111 comma 3 Cost., che riconosce al solo imputato il diritto di disporre «del tempo e delle condizioni necessari per

Nello stesso senso, FERRUA, Paolo, La ragionevole durata del processo tra Costituzione e Convenzione europea, cit.; GIOSTRA, Glauco, Prima lezione sulla giustizia penale, Laterza, Bari-Roma, 2020, p. 77 s.; KOSTORIS, Roberto E., La ragionevole durata del processo nella Convenzione europea dei diritti dell'uomo e nell'art. 111 Cost., in KOSTORIS, Roberto E. (a cura di), La ragionevole durata del processo. Garanzie ed efficienza della giustizia penale, Giappichelli, Torino, 2005, p. 3 ss. V. altresì FLICK, Giovanni Maria, Dall'oblio alla memoria: o viceversa? Divagazioni sulla prescrizione, in Cass. pen., 2020, p. 901; NAPPI, Aniello, Prescrizione e ragionevole durata del processo, in Giustizia insieme, 23 marzo 2020; SIRACUSANO, Fabrizio, La durata ragionevole del processo quale "metodo" della giurisdizione, in Dir. pen. proc., 2003, p. 758 ss. Annovera la ragionevole durata tra $\mathrm{i}$ «riferimenti ordinamentali» che devono costituire «la premessa delle scelte legislative» SPANGHER, Giorgio, Considerazioni sul processo "criminale" italiano, Giappichelli, Torino, 2015, p. 96.

7 AMODIO, Ennio, La procedura penale dal rito inquisitorio al giusto processo, in Cass. pen., 2003, p. 1422; AMODIO, Ennio, Giusto processo, procès équitable e fair trial: la riscoperta del giusnaturalismo processuale in Europa, in Riv. it. dir. proc. pen., 2003, p. 93 ss., spec. 97 ss.; AMODIO, Ennio, Ragionevole durata del processo, abuse of process e nuove esigenze di tutela dell'imputato, in Dir. pen. proc., 2003, p. 797 ss., che, a sostegno della sua tesi, approfondisce altresì (p. 799 s.) il rapporto nei Paesi di common law tra durata irragionevole del processo e abuse of process, concetto riferito ai soli comportamenti dilatori della pubblica accusa e non dell'imputato. 
preparare la sua difesa», nonché il fatto che le altre norme processuali della Carta fondamentale - artt. 13, 24 comma 2, 25 comma 1, 27 comma 2 Cost. - sarebbero intese come garanzie soggettive ${ }^{8}$, comprese quelle che formalmente non indicano l'imputato come destinatario (art. 13 comma 4 Cost. sui «termini massimi della carcerazione preventiva», la cui fissazione è demandata alla legge) ${ }^{9}$. Il dichiarato (e condivisibile) intento di questa impostazione consiste nel preservare il diritto di difesa contro gli abusi dell'autorità statale, che, col pretesto di contrarre i tempi procedimentali, potrebbe ledere arbitrariamente le garanzie dell'indagato e dell'imputato ${ }^{10}$.

La tesi si espone però ad alcune significative obiezioni, e, in ultima analisi, non pare necessaria per tutelare adeguatamente le facoltà difensive, presentando al contempo possibili effetti indesiderati di rilievo.

Innanzitutto, il tenore testuale della disposizione è difficilmente controvertibile: a differenza dell'art. 6 par. 1 CEDU, è la stessa formulazione dell'art. 111 comma 2 Cost. a delineare la garanzia in termini oggettivi ${ }^{11}$. Inoltre, la dimensione della ragionevole durata come «esigenza di buona amministrazione della giustizia» è connaturata allo stesso procedimento penale e può essere considerata un corollario dell'art. 3 Cost. ${ }^{12}$. Pure le altre garanzie processuali sancite dalla Costituzione presentano, accanto alla connotazione soggettiva, anche una correlativa natura di «garanzie oggettive di giustizia», ivi compreso il diritto di difesa, come

8 AMODIO, Ennio, Ragionevole durata del processo, abuse of process e nuove esigenze di tutela dell'imputato, cit., p. 797 s., il quale precisa che pure il pubblico ministero è titolare di un «diritto alla celerità processuale», benché di rango inferiore a quello dell'imputato.

9 AMODIO, Ennio, Ragionevole durata del processo, abuse of process e nuove esigenze di tutela dell'imputato, cit., p. 797 nota 4.

10 AMODIO, Ennio, Giusto processo, procès équitable $e$ fair trial: la riscoperta del giusnaturalismo processuale in Europa, cit., p. 93 ss.; AMODIO, Ennio, Ragionevole durata del processo, abuse of process e nuove esigenze di tutela dell'imputato, cit., p. 797 ss.

11 FERRUA, Paolo, Il 'giusto processo', 3 ${ }^{\mathrm{a}}$ ed., Zanichelli, Bologna, 2012, p. 109 s. Ritiene che la lettura dell'art. 111 comma 2, secondo periodo, Cost. come garanzia esclusivamente soggettiva sia una soluzione «esegeticamente impraticabile» GIOSTRA, Glauco, Prima lezione sulla giustizia penale, cit., p. 77.

12 Così FERRUA, Paolo, Il 'giusto processo', cit., p. 110 s. 
affermato anche dalla Consulta in relazione all'assistenza tecnica, che appunto è irrinunciabile ${ }^{13}$. I sostenitori dell'esclusiva natura soggettiva della ragionevole durata affermano che la fondamentale differenza tra la difesa come "garanzia oggettiva" - necessaria all'accertamento processuale e quindi obbligatoria - e la ragionevole durata nel suo significato oggettivo consisterebbe in una profonda divergenza di finalità: un potenziamento della protezione dell'imputato nel primo caso, un'inaccettabile erosione di quest'ultima nel secondo, in nome di esigenze collettive di difesa sociale e di celere definizione dei procedimenti ${ }^{14}$. Tale argomentazione, tuttavia, non convince: la dimensione oggettiva della ragionevole durata, strettamente connessa al concetto di efficienza processuale ${ }^{15}$, non esclude ma anzi ricomprende quella soggettiva, implicando l'attribuzione all'imputato del diritto a farsi giudicare in un tempo ragionevole; al contrario, il correlativo diritto non presuppone necessariamente che il principio assuma la portata di «garanzia oggettiva di buon funzionamento della giustizia» ${ }^{16}$. Non pare dunque corretto ritenere che la tesi oggettiva neghi la concezione della ragionevole durata come diritto dell'imputato: non si esclude la sua natura di diritto, ma lo si inserisce in una prospettiva più ampia, al fine di scongiurare situazioni paradossali. Infatti, a differenza dell'impostazione oggettiva, la tesi della ragionevole durata intesa soltanto come diritto dell'imputato, portata alle sue estreme conseguenze, non è ad esempio idonea a limitare il rischio di un'abusiva e incontrollata proliferazione delle garanzie difensive, potenzialmente capace di paralizzare di fatto il corso dei processi, poiché l'esigenza di un procedimento dalla durata ragionevole non troverebbe

13 FERRUA, Paolo, Il 'giusto processo', cit., p. 110, nota 61. Ci si riferisce a Corte cost., sent. 10 ottobre 1979, n. 125, in Cass. pen., 1980, p. 629 ss. e a Corte cost., sent. 22 dicembre 1980, n. 188, in Cass. pen., 1981, p. 961 ss.

14 AMODIO, Ennio, Giusto processo, procès équitable $e$ fair trial: la riscoperta del giusnaturalismo processuale in Europa, cit., p. 98.

15 Valore, quest'ultimo, ritenuto di rango costituzionale già da prima della riforma dell'art. 111 Cost.: Corte cost., sent. 22 ottobre 1996, n. 353, in Cass. pen., 1997, p. 647 ss., 1276. Sul punto, GREVI, Vittorio, Il principio della «ragionevole durata» come garanzia oggettiva del «giusto processo» penale, cit., p. 3208.

16 Cfr. FERRUA, Paolo, La ragionevole durata del processo tra Costituzione e Convenzione europea, cit. V. altresì GREVI, Vittorio, Il principio della «ragionevole durata» come garanzia oggettiva del «giusto processo» penale, cit., p. 3212. 
alcuna tutela qualora fosse in contrasto con l'interesse dell'imputato ${ }^{17}$. La ragionevole durata come garanzia oggettiva dell'esercizio della giurisdizione conferisce invece al legislatore la possibilità di predisporre strumenti a tutela dei tempi della giustizia per evitare simili situazioni ${ }^{18}$, a prescindere dal contegno processuale dell'imputato ${ }^{19}$.

17 GREVI, Vittorio, Il principio della «ragionevole durata» come garanzia oggettiva del «giusto processo» penale, cit., p. 3211; FERRUA, Paolo, La ragionevole durata del processo tra Costituzione e Convenzione europea, cit.; GIOSTRA, Glauco, Prima lezione sulla giustizia penale, cit., p. 78; KOSTORIS, Roberto E., La ragionevole durata del processo nella Convenzione europea dei diritti dell'uomo e nell'art. 111 Cost., in KOSTORIS, Roberto E. (a cura di), La ragionevole durata del processo. Garanzie ed efficienza della giustizia penale, cit., p. 9 s. Del resto, gli stessi sostenitori della ragionevole durata come garanzia esclusivamente soggettiva cercano di introdurre correttivi per evitare epiloghi paradossali, affermando che «i ritardi e gli intralci causati dallo stesso imputato fanno prevalere, in via di eccezione, l'interesse pubblico e giustificano la repressione degli abusi» (benché la medesima dottrina, poco dopo, osservi come la categoria di common law dell'abuse of process sia riferibile ai soli comportamenti della pubblica accusa): così AMODIO, Ennio, Ragionevole durata del processo, abuse of process e nuove esigenze di tutela dell'imputato, cit., p. 798 ss., spec. p. 798.

18 Come emerge dalla lettera dell'art. 111 comma 2, secondo periodo, Cost., si tratta di una prerogativa legislativa e non certo giurisprudenziale. Sul punto, FERRUA, Paolo, Il 'giusto processo', cit., p. 116 s. Si registra tuttavia un'inaccettabile tendenza giudiziale a sostituirsi al legislatore, mediante interpretazioni praeter legem (quando non addirittura contra legem) e discutibili prospettazioni de iure condendo: v. ad esempio, in tema di abuso del processo, Cass., sez. un., 29 settembre 2011, n. 155, Rossi, in Cass. pen., 2012, p. 2410 ss., con nota di CAPRIOLI, Francesco, Abuso del diritto di difesa e nullità inoffensive; in tema di immutabilità del giudice ex art. 525 comma 2 Cost., Corte cost., sent. 29 maggio 2019, n. 132, in Dir. pen. cont., 3 giugno 2019, e Cass., sez. un., 30 maggio 2019, n. 41736, Bajrami Klevis, in Guida dir., 2019, n. 44, p. 93 e 95, e ivi, n. 46, p. 64 ss. Per un condivisibile commento critico, FERRUA, Paolo, Il sacrificio dell'oralità nel nome della ragionevole durata: i gratuiti suggerimenti della Corte costituzionale al legislatore, in Arch. pen. - Riv. Web, 2019, n. 2.

19 La Corte europea dei diritti dell'uomo considera comunque titolare del diritto ad ottenere una decisione entro tempi ragionevoli anche la persona che fa valere contestazioni di natura civile nel processo penale, poiché l'art. 6 par. 1 CEDU attribuisce tale diritto pure al soggetto che aziona diritti di carattere civile: Corte eur. dir. uomo, 29 ottobre 1991, Court (Plenary), Helmers c. Svezia, in hudoc.echr.coe.int/eng?i=001-57701; Corte eur. dir. uomo, sez. III, 26 ottobre 1999, Maini c. Francia, par. 35, in hudoc.echr.coe.int/fre?i=001-62952. Per alcune pronunce, è altresì legittimata la persona offesa prima della 
Dalla nozione di ragionevole durata come diritto soggettivo discende altresì la risarcibilità del danno da procedimento irragionevolmente lungo. La Corte europea dei diritti dell'uomo ha nel tempo formulato dei parametri per valutare l'irragionevolezza dei tempi procedimentali nel caso concreto, mediante un giudizio da effettuare ex post e purché - come prescrive l'art. 35 par. 3 CEDU - il pregiudizio subìto dal ricorrente sia importante ${ }^{20}$ : la complessità del procedimento (ad esempio per il numero delle parti, per la quantità delle prove orali da acquisire o dei documenti da assumere, per la necessità di ricorrere a traduttori e interpreti, per la transnazionalità del reato), il comportamento delle autorità statali (maggiore o minore solerzia nell'espletare le attività del procedimento) e il contegno del ricorrente (eventuali condotte dilatorie) ${ }^{21}$.

costituzione di parte civile, qualora compia atti che dimostrino l'interesse ad ottenere la riparazione del danno subito in conseguenza della lesione di un diritto di natura civilistica: Corte eur. dir. uomo, sez. I, 7 dicembre 2017, Arnoldi c. Italia, in Cass. pen., 2018, p. 1357 ss.; Corte eur. dir. uomo, sez. III, 24 febbraio 2005, Sottani c. Italia, in hudoc.echr.coe.int/eng ?i=001-70625. In dottrina, GUALTIERI, Piero, Durata ragionevole del processo e persona offesa, in Dir. pen. proc., 2012, p. 1013 ss.; LAVARINI, Barbara, La ragionevole durata del processo come garanzia soggettiva, in Leg. pen., 31 dicembre 2019, p. 3.

Da altro punto di vista, è però difficile pervenire ad una pronuncia di incostituzionalità unicamente sulla base dell'art. 111 comma 2 Cost., considerate al contempo l'ampiezza dell'aggettivo "ragionevole" e la possibilità di dichiarare l'illegittimità costituzionale solo in caso di manifesta irragionevolezza: sul punto, MARZADURI, Enrico, in CANZIO, Giovanni - MARZADURI, Enrico SILVESTRI, Giovanni, Preclusioni processuali e ragionevole durata del processo, in Criminalia, 2008, p. 252.

A pena di irricevibilità del ricorso. L'importanza del pregiudizio si desume dalla natura del diritto, dalla rilevanza della violazione sull'esercizio del diritto, dalle conseguenze sulla posizione del ricorrente: FERRUA, Paolo, La ragionevole durata del processo tra Costituzione e Convenzione europea, cit.

21 Per approfondimenti, NACAR, Barbara, I termini e la ragionevole durata del processo penale, cit., p. 82 ss.; BUZZELLI, Silvia, $\$ 10-14$, in BUZZELLI, Silvia - CASIRAGHI, Roberta - CASSIBBA, Fabio - CONCOLINO, Paola - PRESSACCO, Luca, Art. 6. Diritto a un equo processo, in UBERTIS, Giulio - VIGANÒ, Francesco (a cura di), Corte di Strasburgo e giustizia penale, Giappichelli, Torino, 2016, p. 143 ss.; FERRUA, Paolo, La ragionevole durata del processo tra Costituzione e Convenzione europea, cit.; UBERTIS, Giulio, Azione penale, contraddittorio e durata ragionevole del processo, in Riv. it. dir. proc. pen., 2005, p. 132 s. 
La disciplina nazionale per l'«equa riparazione» da eccessiva durata dei procedimenti è stata delineata dalla legge n. $89 \mathrm{del} 2001^{22}$, anche nota come "legge Pinto", modificata a più riprese dal legislatore e dalla Consulta $^{23}$. Essa, pur prevedendo all'art. 2 comma 1 limiti temporali entro cui la durata si considera comunque ragionevole (tre anni per i procedimenti di primo grado, due per quelli in appello e uno per quelli in cassazione ${ }^{24}$ ), contempla ${ }^{25}$ una valutazione concreta dei tempi processuali, fondata sui parametri dell'art. 2 comma 2 per stabilire l'an dell'«equa riparazione» ${ }^{26}$, e su quelli dell'art. 2-bis comma 2 per determinarne il quantum ${ }^{27}$.

22 Legge 24 marzo 2001, n. 89, intitolata «Previsione di equa riparazione in caso di violazione del termine ragionevole del processo e modifica dell'articolo 375 del codice di procedura civile».

23 Corte cost., sent. 10 luglio 2019, n. 169, in Gazz. uff., 17 luglio 2019, n. 17; Corte cost., sent. 26 aprile 2018, n. 88, in Gazz. uff., 2 maggio 2018, n. 18; Corte cost., sent. 19 febbraio 2016, n. 36, in Gazz. uff., 24 febbraio 2016, n. 8; Corte Cost., sent. 23 luglio 2015, n. 184, in Gazz. uff., 29 luglio 2015, n. 30. Per alcuni ragguagli, v. BUZZELLI, Silvia, $\S 15$, in BUZZELLI, Silvia - CASIRAGHI, Roberta - CASSIBBA, Fabio - CONCOLINO, Paola - PRESSACCO, Luca, Art. 6. Diritto a un equo processo, in UBERTIS, Giulio - VIGANÒ, Francesco (a cura di), Corte di Strasburgo e giustizia penale, cit., p. 148 s.

24 Il termine ragionevole si reputa ugualmente rispettato ove la durata complessiva non superi sei anni. Ai fini della legge Pinto, il dies a quo del processo penale coincide con l'assunzione delle qualità di imputato, parte civile o responsabile civile, oppure con la conoscenza legale della conclusione delle indagini da parte dell'indagato (art. 2 comma 2-bis, quarto periodo), ovvero, a seguito di Corte cost. n. $184 / 2015$, cit., incomincia «quando l'indagato, in seguito a un atto dell'autorità giudiziaria, ha avuto conoscenza del procedimento penale a suo carico».

Oltre a «rimedi preventivi» come l'istanza acceleratoria ex art. 1-ter, cui è subordinata l'ammissibilità della successiva domanda di risarcimento.

26 L'art. 2 comma 2 legge n. 89/2001 dispone che «nell'accertare la violazione il giudice valuta la complessità del caso, l'oggetto del procedimento, il comportamento delle parti e del giudice durante il procedimento, nonché quello di ogni altro soggetto chiamato a concorrervi o a contribuire alla sua definizione».

27 Ai sensi dell'art. 2-bis comma 2 legge n. 89/2001, «l'indennizzo è determinato a norma dell'articolo 2056 del codice civile, tenendo conto:

a) dell'esito del processo nel quale si è verificata la violazione di cui al comma 1 dell'articolo 2;

b) del comportamento del giudice e delle parti;

c) della natura degli interessi coinvolti;

d) del valore e della rilevanza della causa, valutati anche in relazione alle condizioni personali della parte». 
Il principio costituzionale della ragionevole durata va comunque considerato sussidiario rispetto agli altri principi del giusto processo ${ }^{28}: \mathrm{i}$ «primari valori di giustizia» - funzione cognitiva del processo, imparzialità del giudice, diritto di difesa - sono cioè logicamente prioritari rispetto alla ragionevole durata e, nel loro contenuto essenziale, non possono cedere di fronte a tentazioni efficientiste ${ }^{29}$. La ragionevole durata va

28 FERRUA, Paolo, Il 'giusto processo', cit., p. 113 ss., per il quale svolge un «ruolo sussidiario, come condizione di efficienza».

29 FERRUA, Paolo, Il 'giusto processo', cit., p. 113 ss. Secondo l'A., la ragionevole durata è logicamente susseguente rispetto a tali valori, venendo in questione solo una volta effettuata la scelta di un determinato «modello processuale, caratterizzato da certe garanzie», come «il contraddittorio davanti a un giudice imparziale». Solo gli ampliamenti del predetto «nucleo essenziale» possono essere bilanciati con la ragionevole durata. Un rafforzamento del diritto di difesa è ad esempio legittimo, ma non potrebbe giungere a paralizzare il processo. Nel medesimo senso, FERRUA, Paolo, La ragionevole durata del processo tra Costituzione e Convenzione europea, cit.; FLICK, Giovanni Maria, Dall'oblio alla memoria: o viceversa? Divagazioni sulla prescrizione, cit., p. 901 s.; GIOSTRA, Glauco, Prima lezione sulla giustizia penale, cit., p. 79, il quale osserva che la particella pronominale «ne», inserita nel secondo periodo dell'art. 111 comma 2 Cost., riferisce la ragionevole durata al processo "giusto", cioè a quello che rispetta le garanzie fondamentali enunciate nel primo periodo dello stesso comma; KOSTORIS, Roberto E., La ragionevole durata del processo nella Convenzione europea dei diritti dell'uomo e nell'art. 111 Cost., in KOSTORIS, Roberto E. (a cura di), La ragionevole durata del processo. Garanzie ed efficienza della giustizia penale, cit., p. 11; MARANDOLA, Antonella, Prescrizione e processo: l'asistematicità dell'attuale disciplina, in Giur. it., 2020, p. 992; MAZZA, Oliviero, La riforma dei due orologi: la prescrizione fra miti populisti e realtà costituzionale, in Sist. pen., 21 gennaio 2020, che parla di «garanzia di secondo grado, volta a soddisfare le primarie esigenze tanto di effettività dei diritti di difesa in senso lato quanto di finalismo rieducativo della pena»; SIRACUSANO, Fabrizio, La durata ragionevole del processo quale "metodo" della giurisdizione, cit., p. 762 ss.; SCALFATI, Adolfo, Processo penale, "ragionevole durata" e recenti proposte, in Cass. pen., 2015, p. 1309 s. Per un diverso punto di vista, GREVI, Vittorio, Alla ricerca di un processo penale «giusto». Itinerari e prospettive, Giuffrè, Milano, 2000, p. 327, secondo cui la ragionevole durata ha un «rango logicamente prioritario» rispetto alle altre garanzie. Ritiene che la ragionevole durata abbia «natura metagiuridica» RICCIO, Giuseppe, Note sulla ragionevole durata nel processo penale, in Cass. pen., 2011, p. 4529 ss., spec. 4530 s., precisando però che detta connotazione non ne presuppone la prevalenza rispetto agli altri valori costituzionali, ma implica soltanto l'obbligo per il legislatore di organizzare la macchina giudiziaria in maniera da giungere a una conclusione in un tempo ragionevole. 
dunque plasmata in ragione di tali valori primari ${ }^{30}$. L'opposta idea di processo, che antepone logicamente la ragionevole durata, svuota la medesima di significato, rischiando di condurre verso orizzonti di giustizia sommaria ${ }^{31}$. Non bisogna cedere alla tentazione di velocizzare il procedimento a scapito delle altre garanzie, bilanciabili con le esigenze di speditezza solo ove non costituiscano parte integrante del predetto contenuto essenziale. In particolare, nell'introdurre limiti in nome della speditezza processuale a una specifica garanzia in cui si esplica il diritto di difesa, il legislatore deve previamente verificare se quest'ultima possa definirsi significativa, cioè non superflua per realizzare la difesa stessa, come si desume dall'art. 111 comma 3 Cost. («la legge assicura che la persona accusata di un reato (...) disponga del tempo e delle condizioni necessari per preparare la sua difesa») e dall'art. 6 par. 3, lett. $c, \mathrm{CEDU}^{32}$. Nel caso in cui essa sia da considerare significativa, il legislatore deve verificare l'idoneità dell'intervento normativo a preservarne l'effettivo esercizio. Sarebbe ad esempio legittima - benché discutibile sotto il profilo dell'opportunità - una riforma dell'art. 108 c.p.p. che, in caso di revoca del precedente avvocato, conceda al difensore subentrante il diritto ad ottenere il termine a difesa una sola volta per ogni fase procedimentale, a meno di specifiche esigenze difensive, tali da giustificare la reiterazione della richiesta. Il termine ex art. 108 c.p.p. è infatti un presidio significativo per l'esercizio del diritto di difesa, ma il suddetto intervento, finalizzato ad evitare dilazioni abusive, non lo limiterebbe al punto da renderlo inoperante o difficilmente operante. Sarebbe al contrario illegittima una riforma che, nell'ipotesi di revoca del difensore, conceda il termine ex art. 108 c.p.p. al nuovo avvocato una sola volta in tutto il procedimento, senza eccezioni: l'effettività della

30 Afferma efficacemente che «la durata del processo è ragionevole quando si estende per il tempo necessario alla ragionevole realizzazione di tutte le garanzie del giusto processo» GIOSTRA, Glauco, Prima lezione sulla giustizia penale, cit., p. 80.

31 FERRUA, Paolo, Il 'giusto processo', cit., p. 114.

32 Sulla distinzione tra necessità e superfluità dei tempi e degli strumenti difensivi, v. LAVARINI, Barbara, La ragionevole durata del processo come garanzia soggettiva, cit., p. 5 ss. 
disposizione, significativa espressione del diritto di difesa, verrebbe compromessa in nome della speditezza ${ }^{33}$.

Il presente contributo, partendo dai dati ufficiali sulla durata e sul carico di lavoro dei procedimenti penali italiani forniti dal Ministero della Giustizia, tenta di individuare i punti deboli del nostro sistema processuale sotto il profilo dell'efficienza, cercando, senza pretesa di esaustività, di proporre soluzioni normative de iure condendo che mettano gli operatori in condizione di concludere i procedimenti in tempi equi, ferme restando le altre garanzie del giusto processo. Non si propongono riforme ampie e velleitarie, ma azioni mirate su istituti esistenti, idonee ad una più celere approvazione legislativa.

Quanto appena osservato rende comunque opportuno un chiarimento: il "processo giusto" non è necessariamente il "processo breve": un processo è giusto se consente di giungere al suo epilogo nel tempo strettamente necessario per garantire il pieno rispetto del diritto di difesa e degli altri valori costituzionali del giusto processo penale ${ }^{34}$, nei modi e coi margini di bilanciamento suddetti. I dati statistici sulla durata dei procedimenti e sulla capacità del sistema giudiziario di smaltire il carico di lavoro, benché essenziali per comprendere e risolvere alcune criticità della giustizia, non sono dunque l'unico indicatore del "livello di attuazione" del giusto processo penale.

\section{Il CARICO DI LAVORO DELLA GIUSTIZIA PENALE ITALIANA.}

Il Ministero della Giustizia fornisce dati analitici sulla ripartizione e sulla definizione del carico giudiziario italiano, da cui si può desumere, in

33 Il legislatore deve compiere tale valutazione anche in relazione agli altri «primari valori di giustizia». Per un efficace esempio in tema di imparzialità giudiziale, v. GIOSTRA, Glauco, Prima lezione sulla giustizia penale, cit., p. 79, che ragiona sulla compatibilità costituzionale di diverse formulazioni della rimessione del processo. Per alcuni cenni sui rapporti tra riti premiali e funzione cognitiva del processo, v. infra, par. 3.

34 Come afferma altresì il giudice delle leggi: Corte cost., sent. 9 luglio 2004, n. 219, in Cass. pen., 2004, p. 3608 ss.; Corte cost., sent. 12 aprile 2005, n. 148, in Cass. pen., 2005, p. 2213 ss. Sul punto, MONGILLO, Vincenzo, Essere e dover essere della prescrizione penale tra diritti fondamentali e neopunitivismo, in Giur. it., 2020, p. 1005. 
una certa misura, la capacità degli uffici di far fronte in tempi ragionevoli ai procedimenti pendenti. In relazione alla giustizia penale, le statistiche più aggiornate riguardano il $2019^{35}$. Si tralasciano, anche ove disponibili, i dati sui primi mesi del 2020, in quanto provvisori e comunque già condizionati dalla situazione eccezionale determinata dalla pandemia di Covid-19. Per motivi di brevità non si considerano la giustizia minorile e la fase di esecuzione. Ci si concentra in particolare sulla magistratura giudicante, pur senza trascurare le procure della Repubblica.

Nel 2019, nelle procure presso i tribunali ordinari sono stati iscritti 1.198 .793 procedimenti penali con "autore noto" (rectius con iscrizione di un indagato nel registro delle notizie di reato), ne sono stati definiti 1.239.055 $5^{36}$ e ne restano pendenti 1.040.689; nelle procure generali presso le corti d'appello i valori sono rispettivamente 105 iscritti, 97 definiti e 66 pendenti; davanti ai giudici di pace 146.933, 153.611 e $101.175^{37}$; dinanzi ai tribunali e relative sezioni $1.113 .926,1.074 .164$ e 1.152.240 (di cui rispettivamente $756.730,731.163$ e 517.053 nella sezione g.i.p.-g.u.p.; 337.557, 323.968 e 600.702 presso il tribunale monocratico di funzione di giudice di primo grado; 4.286, 4.641 e 4.697 di fronte al tribunale monocratico in sede di appello contro sentenze del giudice di pace; $15.091,14.119$ e 29.373 davanti al tribunale collegiale; 262, 273 e 415 dinanzi alla corte d'assise); 112.686, 115.130 e 263.319

35 I dati seguenti sono tratti da MINISTERO DELLA GIUSTIZIA - DIPARTIMENTO DELL'ORGANIZZAZIONE GIUDIZIARIA, DEL PERSONALE E DEI SERVIZI - DIREZIONE GENERALE DI STATISTICA E ANALISI ORGANIZZATIVA PRESSO IL MINISTERO DELLA GIUSTIZIA (DG-STAT), Statistiche giudiziarie. Area penale, in webstat.giustizia.it (consultato l'8 luglio 2020). Le statistiche qui citate si riferiscono ai soli procedimenti con "autore noto" (rectius, con l'iscrizione del nominativo dell'indagato nel registro delle notizie di reato o, per gli uffici di primo e secondo grado e per la cassazione, con l'attribuzione del reato a un determinato imputato, a prescindere da un eventuale successivo accertamento definitivo di responsabilità).

36 Di cui 1.053.264 iscritti, 1.082 .869 definiti e 889.096 pendenti per reati ordinari, 140.574 iscritti, 150.888 definiti e 145.164 pendenti per fattispecie di competenza del giudice di pace e 4.955 iscritti a fronte di 5.298 definiti e 6.429 pendenti per reati di competenza della direzione distrettuale antimafia e antiterrorismo.

37 Di cui 62.154 iscritti a fronte di 67.999 definiti e 89.432 pendenti in dibattimento e 84.779 iscritti, 85.612 definiti e 11.743 pendenti presso il giudice di pace in funzione di giudice per le indagini preliminari. 
in corte d'appello (di cui rispettivamente 110.489, 112.974 e 260.946 nella sezione penale; 599, 579 e 659 in corte d'assise d'appello); 50.801, 51.831 e 23.579 in cassazione.

Un indicatore della durata dei procedimenti è il c.d. disposition time, utilizzato soprattutto nei rapporti periodici della CEPEJ ${ }^{38}$ : è il rapporto tra i procedimenti pendenti alla fine dell'anno di riferimento e quelli definiti nel medesimo anno, moltiplicato per 365. Esso non coincide necessariamente coi tempi reali, ma è una stima che calcola $i$ tempi prevedibili per definire i procedimenti in corso, presupponendo di mantenere lo stesso ritmo di smaltimento; tale valore è meno sensibile alla composizione degli affari pendenti e ad eventuali criteri di priorità adottati, di fatto o mediante circolari, dagli uffici ${ }^{39}$.

Ad esempio, il disposition time nel 2019 è di 307 giorni nella procura presso il tribunale ordinario, 392 giorni in tribunale (in particolare, 258 nella sezione g.i.p.-g.u.p., 677 davanti al tribunale monocratico e 759 dinanzi al tribunale collegiale ${ }^{40}$ ), 240 giorni davanti al giudice di pace (480 in dibattimento e 50 come giudice per le indagini preliminari), 835 giorni in corte d'appello, e 166 giorni in cassazione ${ }^{41}$.

Alcune statistiche riferite all'anno giudiziario 2018/2019 mostrano un calo delle pendenze presso le procure della Repubblica del $9 \%$ rispetto all'anno prima, dovuto anche ad una correlativa flessione del 2,3\% dei procedimenti iscritti ${ }^{42}$.

38 Commissione per l'Efficienza della Giustizia, organismo del Consiglio d'Europa che monitora l'efficienza dei procedimenti giudiziari degli Stati membri.

39 Al riguardo, MINISTERO DELLA GIUSTIZIA - DIREZIONE GENERALE DI STATISTICA E ANALISI ORGANIZZATIVA, La durata dei procedimenti civili. I principali indicatori a confronto. Anni 2012-2019, in webstat.giustizia.it (consultato l'8 luglio 2020).

40 Il disposition time per le corti d'assise è invece di 555 giorni.

${ }^{41}$ Questi valori attualmente non presenti sul sito webstat.giustizia.it (consultato l'8 luglio 2020), sono stati calcolati autonomamente a partire dai dati sui procedimenti pendenti e definiti ivi riportati, con approssimazione all'unità.

${ }^{42}$ CORTE SUPREMA DI CASSAZIONE - MAMMONE, Giovanni, Relazione sull'amministrazione della giustizia nell'anno 2019, in www.cortedicassazione. it, 31 gennaio 2020 , p. $25 \mathrm{~s}$. 


\section{SEgUE: GLI UfFICI G.I.P.-G.U.P., I TRIBUNALI MONOCRATICI E COLLEGIALI.}

Ulteriori dati ministeriali riferiti ai soli uffici giudicanti ${ }^{43}$ indicano, da un punto di vista diacronico, un incremento percentuale delle pendenze sostanzialmente costante dal 2004 al 2013, con una decrescita graduale dall'anno successivo fino al $2019^{44}$ e con picchi del $+5,1 \%$ rispetto all'anno precedente nel 2006 e del -8,0\% nel 2016.

Attenzione particolare merita il tribunale ordinario.

Benché, dopo anni di aumenti, le pendenze complessive diminuiscano ininterrottamente dal 2016 giungendo nel 2019 a 1.152.240 procedimenti in corso ${ }^{45}$, la situazione preoccupa sotto alcuni profili.

Innanzitutto, il dato sulla diminuzione delle pendenze pare contraddittorio rispetto a quello sul numero di procedimenti iscritti e definiti: come osservato, nonostante vengano conclusi meno procedimenti di quelli iscritti ${ }^{46}$, le pendenze si riducono ugualmente. Ciò potrebbe dipendere da particolari criteri di computo, oppure da incompletezze nelle procedure di rilevazione o nella comunicazione dei dati da parte di alcuni uffici giudiziari.

Nondimeno, anche tenendo in considerazione le statistiche attestanti il decremento degli affari in corso, il continuo calo rilevato nei procedimenti pendenti all'ufficio g.i.p.-g.u.p., giunti a 517.053 nel $2019^{47}$,

43 Fonte: MINISTERO DELLA GIUSTIZIA - DIPARTIMENTO DELL'ORGANIZZAZIONE GIUDIZIARIA, DEL PERSONALE E DEI SERVIZI - DIREZIONE GENERALE DI STATISTICA E ANALISI ORGANIZZATIVA, Monitoraggio della giustizia penale - anni 2003 - I trimestre 2020, in www.giustizia.it, 7 luglio 2020 (consultato il 22 luglio 2020). In mancanza di ulteriori specificazioni, le statistiche del presente paragrafo riportate di seguito sono tratte da questa fonte.

Di seguito si riportano le variazioni totali dei procedimenti pendenti rispetto all'anno precedente dal 2004 al 2019, comprensive del giudice di pace: $5,0 \%,-0,5 \%, 5,1 \%, 0,6 \%, 0,4 \%, 2,3 \%, 4,6 \%, 2,8 \%, 4,4 \%, 2,4 \%,-1,0 \%$, $0,1 \%,-8,0 \%,-1,8 \%,-1,7 \%,-1,2 \%$.

45 Nel 2015 le pendenze avevano raggiunto il massimo storico della rilevazione in esame, pari a 1.313.577 procedimenti.

46 È dal 2017 che, alla voce "tribunale e relative sezioni”, gli affari iscritti superano i definiti.

47 Si registra una diminuzione continua dal 2013 (anno in cui il numero era pari a 767.586). Nel 2017 le pendenze erano 558.776, nel 2018 531.228. Nel 2004 
non rincuora ove letto assieme alle risultanze del tribunale monocratico e di quello collegiale: i processi da definire presso il primo ammontano nel 2019 a 605.399 e sono in aumento da alcuni anni ${ }^{48}$, così come quelli dinanzi al secondo, pari nel 2019 a $29.373^{49}$, nonostante il calo delle sopravvenienze presso i tribunali pari all'1,7\% nell'anno giudiziario 2018/201950. Dal $2017 / 2018$ al 2018/2019, la durata media dei procedimenti di primo grado è passata da 378 a 392 giorni $^{51}$.

La costante diminuzione degli affari dinanzi alla sezione g.i.p.g.u.p. e il contemporaneo aumento di quelli davanti al giudice monocratico o collegiale potrebbe spiegarsi, almeno in parte, con la scarsa attrattività dei riti premiali. Si stima infatti che le sezioni g.i.p.-g.u.p. abbiano definito con riti alternativi solo il 6\% del contenzioso nell'anno giudiziario 2017/2018 e il $7 \%$ in quello successivo, nonché il $4 \%$ con decreto penale esecutivo (i decreti penali sono considerati autonomamente rispetto agli altri procedimenti speciali) $^{52}$. È pur vero che, al netto dei provvedimenti di archiviazione, la percentuale in tali sezioni sale al $15,51 \%$ per i decreti penali esecutivi e al $30,71 \%$ per le definizioni a seguito di altro rito alternativo $^{53}$. D'altro canto, pure davanti al tribunale monocratico, nel

le pendenze dinanzi a tale sezione erano addirittura 810.156.

Dopo il sensibile calo da 565.596 nel 2015 a 534.037 nel 2016, si è verificato un incremento continuo delle trattazioni in corso davanti al tribunale monocratico, con 578.760 pendenze nel 2017 e 597.657 nel 2018.

49 L'aumento è ininterrotto dal 2012 ed è pari a circa un migliaio di procedimenti in più all'anno. Nel 2017 le pendenze erano 27.459, nel 2018 sono lievitate sino a 28.192 .

50 Fonte: CORTE SUPREMA DI CASSAZIONE - MAMMONE, Giovanni, Relazione sull'amministrazione della giustizia nell'anno 2019, cit., p. 25, secondo cui tale dato dimostra la «crescente sofferenza organizzativa» degli uffici giudiziari in esame.

51 Nel 2016/2017 la durata era pari a 369 giorni. Fonte: CORTE SUPREMA DI CASSAZIONE - MAMMONE, Giovanni, Relazione sull'amministrazione della giustizia nell'anno 2019, cit., p. 24.

52 Fonte: CORTE SUPREMA DI CASSAZIONE - MAMMONE, Giovanni, Relazione sull'amministrazione della giustizia nell'anno 2019, cit., p. 25 e 27.

53 Le percentuali, approssimate alla seconda cifra decimale, sono state ottenute elaborando i dati numerici riportati in webstat.giustizia.it (consultato l'8 luglio 2020), secondo cui, nel 2019, i provvedimenti di archiviazione ammontano a 467.524 , le sentenze a seguito di rito alternativo a 51.809 , i decreti penali di condanna esecutivi a 26.165 e i decreti che dispongono il giudizio a 90.755 . 
2019 solo l'8,46\% dei processi di primo grado con autore noto definiti mediante sentenza si è concluso con patteggiamento, mentre il 10,96\% con giudizio abbreviato ${ }^{54}$. Nei dati sugli uffici g.i.p.-g.u.p. la definizione a seguito di messa alla prova è verosimilmente ricompresa nella voce sui riti alternativi; manca invece ogni riferimento al probation nelle citate statistiche sul tribunale monocratico di primo grado.

Una maggiore difficoltà nel definire l'arretrato per il giudice monocratico rispetto ad altri organi è, seppur non giustificabile, perlomeno comprensibile, considerata la complessa attività istruttoria dibattimentale e i numerosi potenziali imprevisti, come i rinvii - anche plurimi - per mancata presentazione di testimoni o la rinnovazione del dibattimento che deve (rectius dovrebbe) conseguire alla sostituzione del giudice ${ }^{55}$. In una certa misura (e fatta salva l'importanza, altrettanto fondamentale, dell'organizzazione degli uffici), la difficoltà nel gestire il carico di lavoro è talvolta giustificata dall'imprescindibile necessità di garantire il contraddittorio nella formazione della prova, l'oralità e l'immediatezza ${ }^{56}$.

Tuttavia, il processo accusatorio funziona se l'imputato - che conserva comunque la facoltà di optare per le modalità dibattimentali - è indotto dal sistema a scegliere riti premiali semplificati in una percentuale rilevante di casi, lasciando al dibattimento solo i giudizi che effettivamente abbisognano della formazione della prova in contraddittorio, più garantita ma anche più onerosa in termini di tempo e di risorse $\mathrm{e}^{57}$.

54 Anche in questo caso, le percentuali, approssimate alla seconda cifra decimale, sono state calcolate sulla base dei dati numerici riportati in webstat.giustizia.it (consultato l'8 luglio 2020), secondo cui, a fronte di un totale di 271.590 procedimenti, ne sono stati definiti 22.964 con patteggiamento e 29.772 con rito abbreviato.

55 L'art. 525 comma 2 c.p.p. è molto chiaro nell'imporre tale regola a pena di nullità assoluta. Tuttavia recenti interpretazioni giurisprudenziali, forzando vistosamente il dato legislativo, hanno ridimensionato la portata applicativa della norma: Cass., sez. un., 30 maggio 2019, n. 41736, Bajrami Klevis, in Guida dir., 2019, n. 44, p. 93 e 95, e ivi, n. 46, p. 64 ss.

56 Volendo, PASCUCCI, Nicola, Azione penale e durata dei procedimenti in Italia $e$ in Europa: alcune osservazioni "dati alla mano", in Cultura giuridica e diritto vivente, p. 29.

57 Secondo CONSO, Giovanni, Introduzione, in BARGIS, Marta (a cura di), Compendio di procedura penale, $9^{\mathrm{a}}$ ed., CEDAM, Milano, 2018, p. LXXXIX, «è proprio l'invocata esperienza anglo-americana a dimostrare come quel celebrato 
Al riguardo, a parte la condivisibile introduzione della sospensione del procedimento con messa alla prova con legge n. 67/2014 e alcuni ritocchi secondari ${ }^{58}$, non si coglie nelle recenti riforme una chiara volontà di valorizzare i riti premiali; emerge anzi un atteggiamento ambiguo, proteso a non scontentare le aspettative sociali ${ }^{59}$.

È pur vero che alcuni procedimenti speciali come l'applicazione della pena su richiesta delle parti e il probation comportano la rinuncia non solo al contraddittorio nella formazione della prova - metodo "principe" per l'accertamento dei fatti, che però l'art. 111 comma 5 Cost. consente di derogare mediante il consenso dell'imputato, come accade nel rito abbreviato in cambio di rilevanti benefici premiali bensì allo stesso accertamento della colpevolezza: una mera valutazione del giudice sull'assenza di cause di non punibilità ex art. 129 c.p.p. non può infatti definirsi tale ${ }^{60}$. Considerato tuttavia, come poc'anzi detto, l'estremamente esiguo livello di adesione ai riti premiali nel processo penale italiano ${ }^{61}$, un ponderato potenziamento degli stessi non sembra

sistema in tanto può porre il dibattimento a simbolo del processo penale, in quanto il dibattimento non sia la regola generale, il rito consueto, la condicio sine qua non. Il che diventa possibile solo grazie alle alternative che ne riducono al massimo l'utilizzazione».

Come lo sconto di pena di un mezzo per le contravvenzioni sottoposte a giudizio abbreviato o le peculiari modalità di conversione della pena detentiva in pena pecuniaria nel procedimento per decreto, ad opera della legge n. $103 / 2017$.

Si considerino, a mero titolo di esempio, l'abolizione del rito abbreviato per i delitti puniti con l'ergastolo con legge n. 33/2019 (su cui v. infra, par. 4), l'introduzione del comma 1-ter nell'art. 445 c.p.p. con legge n. 3/2019 e le modifiche agli artt. 438 commi 2 e 6-bis e 464 comma 1 c.p.p. con legge n. $103 / 2017$.

60 FERRUA, Paolo, Il 'giusto processo', cit., p. 172 ss. In relazione alla messa alla prova, la dottrina ha individuato diversi orientamenti giurisprudenziali, più o meno inclini a valorizzare la componente accertativa del rito: CONTI, Carlotta, La messa alla prova tra le due Corti: aporie o nuovi paradigmi?, in Dir. pen. proc., 2018, p. 666 ss. Occorre però ribadire che una valutazione "in negativo" ex art. 129 c.p.p. non può in alcun caso costituire accertamento di responsabilità.

61 Neppure l'introduzione nel 2003 del c.d. patteggiamento "allargato" ha prodotto effetti deflativi di rilievo. All'indomani di tale riforma, in dottrina erano invece emerse preoccupazioni nei confronti di un assetto che avrebbe potuto potenzialmente portare al ribaltamento - non solo in astratto ma anche in 
idoneo a comportare la generalizzazione di modelli non cognitivi, ma contribuirebbe semplicemente a decongestionare la giustizia penale con effetti benefici sulla qualità dell'accertamento nei restanti processi, cui potrebbero così dedicarsi maggiori attenzioni ed energie. Dal punto di vista costituzionale, un rafforzamento del patteggiamento e della messa alla prova pare senz'altro legittimo, purché circoscritto entro limiti legislativamente predefinitíi ${ }^{62}$. Del resto, la richiesta di riti alternativi è una delle principali modalità di esercizio del diritto di difesa, come più volte ribadito dalla Corte costituzionale ${ }^{63}$. La regola che subordina la

concreto - del rapporto regola-eccezione tra modello processuale cognitivo e non cognitivo: KOSTORIS, Roberto E., Con il nuovo «patteggiamento allargato» il rischio di una gigantesca negoziazione, in Guida dir., 2003, n. 25, p. 9 s.

62 La Consulta ha ad esempio "salvato" il c.d. patteggiamento allargato in ragione delle limitazioni oggettive, soggettive e premiali previste dal legislatore, che lo differenziano dal patteggiamento tradizionale: Corte cost., sent. 9 luglio 2004, n. 219, in Cass. pen., 2004, p. 3608 ss.

63 Corte cost., sent. 14 febbraio 2020, n. 19, in Gazz. uff., $1^{\text {a }}$ serie speciale, n. 8 del 2020, p. 27 ss.; Corte cost., sent. 11 aprile 2019, n. 82, in Guida dir., 2019, n. 24, p. 68 ss.; Corte cost., sent. 5 luglio 2018, n. 141, in Guida dir., 2018, n. 32, p. 54 ss.; Corte cost., sent. 17 luglio 2017, n. 206, in Guida dir., 2017, n. 39, p. 68 ss.; Corte cost., 21 luglio 2016, n. 201, in Cass. pen., 2016, p. 4052 ss.; Corte cost., sent. 5 dicembre 2014, n. 273, in Cass. pen., 2015, p. 580 ss.; Corte cost., sent. 26 ottobre 2012, n. 237, in Cass. pen., 2013, p. 141 ss.; Corte cost., sent. 9 luglio 2004, n. 219, cit.; Corte cost., sent. 25 maggio 2004, n. 148, in Cass. pen., 2004, p. 3543 ss.; Corte cost., sent. 29 dicembre 1995, n. 530, in Cass. pen., 1996, p. 1084 ss.; Corte cost., sent. 11 dicembre 1995, n. 497, in Riv. it. dir. proc. pen., 1996, p. 832 ss.; Corte cost., sent. 11 marzo 1993, n. 76, in Cass. pen., 1993, p. 1354 ss.

La messa alla prova, inoltre, nonostante le criticità sotto il profilo della presunzione di non colpevolezza a causa dell'espletamento di un programma trattamentale senza una previa condanna, presenta altresì un'importante valenza rieducativa, che la differenzia dal patteggiamento: v., per tutti, Corte cost., sent. 27 aprile 2018, n. 91, in Gazz. uff., $1^{\text {a }}$ serie speciale, n. 18 del 2 maggio 2018, p. 37 ss., la quale, dopo aver fugato i dubbi di legittimità dell'istituto anche in relazione all'art. 27 comma 2 Cost., individua analogie e differenze rispetto all'applicazione della pena su richiesta delle parti e riconosce la natura rieducativa e risocializzante del probation. Come osserva parte della dottrina (CONTI, Carlotta, La messa alla prova tra le due Corti: aporie o nuovi paradigmi?, cit., p. 680), l'estensione agli adulti della messa alla prova, prima riservata ai soli minorenni, tratteggia inoltre scenari inediti: abbandonando le tradizionali sanzioni penali pecuniarie e detentive, apre la strada ad un ripensamento dell'intervento sanzionatorio in un'ottica non carcerocentrica, 
pena all'accertamento della responsabilità, implicita nel nostro sistema costituzionale, può ritenersi parzialmente disponibile, cioè derogabile col consenso dell'imputato (diverso da quello ex art. 111 comma 5 Cost., riferito invece non all'accertamento in sé, ma al metodo con cui di regola si compie l'accertamento), accompagnato dalla predetta valutazione negativa giudiziale ex art. 129 c.p.p. ${ }^{64}$.

\section{Segue: le corti d'Assise.}

I numeri delle pendenze in corte d'assise sono molto più contenuti ed oscillano tra i 461 del 2005 e i 332 del 2016. Nel 2017 erano pari a 344, nel 2018 a 423, nel 2019 a $415^{65}$. La situazione, sostanzialmente stazionaria, rischia tuttavia di essere compromessa da una recente riforma: in base alla legge 12 aprile 2019, n. 33, non è più ammesso il giudizio abbreviato per i delitti puniti con la pena dell'ergastolo ${ }^{66}$.

sempre più imperniato su trattamenti individualizzati e variabili in ragione delle esigenze risocializzanti del singolo soggetto.

64 In tal senso, in relazione al patteggiamento, FERRUA, Paolo, Il 'giusto processo', cit., p. 172 ss., il quale parla di «volontà dell'imputato che nel corso del processo concordi con la controparte l'applicazione della pena».

65 Fonte: MINISTERO DELLA GIUSTIZIA - DIPARTIMENTO DELL'ORGANIZZAZIONE GIUDIZIARIA, DEL PERSONALE E DEI SERVIZI - DIREZIONE GENERALE DI STATISTICA E ANALISI ORGANIZZATIVA, Monitoraggio della giustizia penale - anni 2003 - I trimestre 2020, cit.

66 La legge ha dettato la preclusione con l'introduzione del comma 1-bis nell'art. 438 c.p.p. ed ha correlativamente soppresso gli ultimi due periodi dell'art. 442 comma 2 c.p.p. Il legislatore ha inoltre modificato altre disposizioni per armonizzare la nuova disciplina con la trama codicistica, nonostante residuino diverse problematiche di coordinamento: v. SPANGHER, Giorgio, Esclusi dall'abbreviato i reati puniti con l'ergastolo (l. n. 33 del 2019), in Il processo, 2019, n. 2, p. 489 ss.; VIGONI, Daniela, Ancora una riforma del giudizio abbreviato: l'inammissibilità per i delitti puniti con l'ergastolo, in Dir. pen. proc., 2019, p. 928. In particolare, sul mancato raccordo della novella con la normativa processuale minorile, in cui l'ergastolo non è applicabile, v. ZAPPULLA, Angelo, Le deroghe al rito ordinario nelle varie fasi del procedimento, in ZAPPALÀ, Enzo (a cura di), La giurisdizione specializzata nella giustizia penale minorile, $3^{\mathrm{a}}$ ed., Giappichelli, Torino, 2019, p. 120 s.

Il legislatore e la Corte costituzionale erano già intervenuti diverse volte sulle norme in esame. Poco dopo l'entrata in vigore del codice di procedura 
A parte l'ambigua espressione utilizzata (si parla di delitti «puniti» con l'ergastolo $)^{67}$, la novella potrebbe anche ingenerare dubbi di legittimità costituzionale sotto i profili della ragionevolezza - creando sperequazioni ingiustificate tra fattispecie - nonché della presunzione di non colpevolezza e del diritto di difesa ${ }^{68}$. È infatti fuorviante considerare l'accesso al giudizio abbreviato come un mero beneficio, accordabile in quanto tale a determinati reati e non ad altri sulla base di scelte discrezionali del

penale, la Consulta dichiarava l'illegittimità per eccesso di delega dell'art. 442 comma 2, secondo periodo, c.p.p., che prevedeva la sostituzione dell'ergastolo con la reclusione di trent'anni. La legge n. 479/1999 (c.d. legge Carotti) ripristinava in seguito la disposizione originaria. L'art. 7 decreto legge $n$. $341 / 2000$, conv. in legge n. 4/2001, prevedeva poi, al comma 1 , che l'espressione «pena dell'ergastolo» di cui all'art. 442 comma 2, ultimo periodo, c.p.p. dovesse intendersi come «ergastolo senza isolamento diurno»e, al comma 2, che l'ergastolo con isolamento diurno, nelle ipotesi di concorso di reati e di continuazione, venisse sostituito con l'ergastolo. Sull'art. 7 comma 1 decreto legge n. 341/2000, conv. in legge n. 4/2001, interveniva in seguito Corte cost., sent. 18 luglio 2013, n. 210, in Gazz. uff., $1^{\text {a }}$ serie speciale, n. 30 del 24 luglio 2013, p. 86 ss.

67 Formulazione che, secondo alcuni, consentirebbe di valutare le circostanze attenuanti ai fini dell'ammissione al rito: PREZIOSI, Stefano, Ergastolo e paradigma punitivo nel fuoco del giudizio abbreviato: linee di intersezione fra diritto e processo penale, in Dir. pen. proc., 2020, p. 254 s., secondo cui una soluzione collegata alla mera pena in astratto sarebbe incostituzionale. Contra VIGONI, Daniela, Ancora una riforma del giudizio abbreviato: l'inammissibilità per i delitti puniti con l'ergastolo, cit., p. 920.

68 In tal senso, DE CARO, Agostino, Le ambigue linee di politica penale dell'attuale legislatore: giudizio abbreviato e reati puniti con la pena dell'ergastolo, in Dir. pen. proc., 2018, p. 1636, il quale ragiona su due proposte di legge che al tempo erano ancora in corso di approvazione; PILLONI, Raffaele, Giustizia penale negoziata e divieto di giudizio abbreviato per i delitti puniti con l'ergastolo, in Arch. pen. - Riv. Web, 2020, n. 1, p. 20 ss. Esclude invece profili di illegittimità costituzionale SPANGHER, Giorgio, Esclusi dall'abbreviato i reati puniti con l'ergastolo (l. n. 33 del 2019), cit., p. 489 ss., «trattandosi di disposizione che riguarda tutti i reati, puniti con la pena massima»; similmente, richiamando le argomentazioni della Consulta in merito alle esclusioni nel c.d. patteggiamento allargato, VIGONI, Daniela, Ancora una riforma del giudizio abbreviato: l'inammissibilità per i delitti puniti con l'ergastolo, cit., p. 929 s., la quale però ritiene configurabile un'illegittimità in relazione ai minorenni, per i quali $a$ priori non è ammesso l'ergastolo. Sono state sollevate questioni di legittimità costituzionale: g.u.p. Trib. La Spezia, ord. 6 novembre 2019, in Gazz. uff., $1^{\text {a }}$ serie speciale, n. 4 del 22 gennaio 2020, p. 20 ss.; Corte assise Napoli, 5 febbraio 2020, in Gazz. uff., $1^{\text {a }}$ serie speciale, n. 27 dell'1 luglio 2020, p. 101 ss. 
legislatore. Tale rito non comporta semplicemente uno sconto di pena, ma implica, come rilevante contropartita, la rinuncia al contraddittorio nella formazione della prova, che è il metodo ordinario - e il più garantista di accertamento processuale ${ }^{69}$. Non si giustificano quindi preclusioni sulla base del tipo di reato, tanto più che, come afferma costantemente la Consulta, la facoltà di chiedere i riti premiali costituisce una delle espressioni più rilevanti del diritto di difesa ${ }^{70}$. Inoltre, quando l'imputato, che è presunto innocente, ritiene infondate le gravi accuse a suo carico, il giudizio abbreviato può rappresentare una via d'uscita più celere dal circuito processuale: potrebbe dunque sostenersi l'irragionevolezza del divieto de quo ex art. 27 comma 2 Cost. $^{71}$.

L'interpolazione in esame non solo si pone in controtendenza rispetto agli attuali orientamenti della Consulta volti a circoscrivere la portata dell'ergastolo ${ }^{72}$, ma contrasta pure con le finalità di efficienza processuale ${ }^{73}$, rischiando di provocare, fra alcuni anni, rilevanti problemi di ragionevole durata dei processi presso le corti d'assise. Infatti, prima della riforma, circa 200 omicidi aggravati su 300 ogni anno erano decisi con giudizio abbreviato dal giudice dell'udienza preliminare ${ }^{74}$. Essi, d'ora in poi, dovranno essere definiti dalle corti d'assise. Detti numeri, non

69 Al riguardo, ORLANDI, Renzo, Procedimenti speciali, in BARGIS, Marta (a cura di), Compendio di procedura penale, cit., p. 669.

70 Per i riferimenti alla giurisprudenza costituzionale, v. supra, nota n. 63.

71 In tal senso, DE CARO, Agostino, Le ambigue linee di politica penale dell'attuale legislatore: giudizio abbreviato e reati puniti con la pena dell'ergastolo, cit., p. 1636. Tale A. afferma altresì, in modo condivisibile, che è scorretto limitare alla sola condanna le valutazioni sull'utilità di questo rito, risolvendosi lo stesso in un vero e proprio giudizio, che può anche concludersi con un'assoluzione.

72 Come osserva DOLCINI, Emilio, La pena ai tempi del diritto penale illiberale, in Dir. pen. cont., 22 maggio 2019, p. 8, il quale cita la sentenza n. 149/2018 della Corte costituzionale.

73 DE CARO, Agostino, Le ambigue linee di politica penale dell'attuale legislatore: giudizio abbreviato e reati puniti con la pena dell'ergastolo, cit., p. 1636.

74 Fonte: CORTE SUPREMA DI CASSAZIONE - MAMMONE, Giovanni, Relazione sull'amministrazione della giustizia nell'anno 2019, cit., p. 26, in cui si manifestano preoccupazioni sotto il profilo della ragionevole durata, anche a causa dell'elevata complessità media di questi procedimenti, prevedendo una triplicazione del carico di lavoro per le corti d'assise. 
elevati in termini assoluti e facilmente riassorbibili dalla sezione g.i.p.g.u.p., risultano estremamente considerevoli se rapportati a quelli dei procedimenti iscritti, definiti e pendenti presso le corti d'assise, pari rispettivamente, come osservato, a 262, 273 e 415 nel 2019. Le probabili conseguenze di questa riforma sono dunque opposte al presumibile intento del legislatore ${ }^{75}$ : non rafforza la risposta statuale contro la criminalità più grave, ma obera l'organo giudicante, allungando inevitabilmente $\mathrm{i}$ tempi decisori ${ }^{76}$ e rischiando di compromettere la dovizia del singolo accertamento. Si potrebbero poi presentare, con maggior frequenza, problemi legati alla decorrenza dei termini massimi di custodia cautelare, effetti disincentivanti nella collaborazione degli imputati per delitti di criminalità organizzata e riflessi su tribunali e corti d'appello, che forniscono alle corti d'assise i giudici togati ${ }^{77}$. Vi è il pericolo di frustrare la domanda di giustizia proprio per i delitti più gravi e, in genere, maggiormente sottoposti all'attenzione mediatica. La riforma, pur coinvolgendo un numero tutto sommato ridotto di procedimenti, ha dunque la capacità di

75 Ad ogni modo, già durante l'iter legislativo vi erano stati espliciti richiami a «prestare molta attenzione ad una analisi costi/benefici tra un messaggio, che si vorrebbe rassicurante, di maggiore severità nei confronti dei colpevoli e il risultato concreto di una diminuita efficienza del sistema complessivo della giustizia penale»: BRUTI LIBERATI, Edmondo, Audizione - Senato della Repubblica, $2^{a}$ Commissione, 12 febbraio 2019, Esame DDL n. 925 in materia di giudizio abbreviato, in www.senato.it, p. 4 .

76 Per preoccupanti, ingiusti ed antieconomici esempi di «ritorni, sbandamenti ed ingiustizie», che la presente riforma può cagionare nelle singole situazioni processuali a seguito della modifica dell'imputazione nel procedimento, v. VALIANI, Teresa (a cura di), Ergastolo, stop all'abbreviato. Intervista al prof. Glauco Giostra, in Giustizia insieme, 5 aprile 2019: per l'intervistato, Prof. Glauco Giostra, la novella rappresenta quindi «un grave fattore di appesantimento e di disordine per la giustizia, ma evidentemente era più importante esibire un'inutile muscolarità sanzionatoria».

77 BRUTI LIBERATI, Edmondo, Audizione - Senato della Repubblica, $2^{a}$ Commissione, 12 febbraio 2019, Esame DDL n. 925 in materia di giudizio abbreviato, cit., p. 4. In argomento, v. altresì MARANDOLA, Antonella, La riforma del giudizio abbreviato: prime questioni applicative ed esegetiche della legge $n .33 \mathrm{del}$ 2019, in Studium iuris, 2019, p. 1429; SPANGHER, Giorgio, Esclusi dall'abbreviato i reati puniti con l'ergastolo (l. n. 33 del 2019), cit., p. 489 ss.; VIGONI, Daniela, Ancora una riforma del giudizio abbreviato: l'inammissibilità per i delitti puniti con l'ergastolo, cit., p. 929. 
alterare in modo negativo, più di tante altre interpolazioni passate, anche la percezione sociale della giustizia ${ }^{78}$.

\section{Segue: I GIUdici di PACE.}

Occorre anche accennare alla giustizia di pace, in cui si registra un decremento delle pendenze dal 2014. Il valore più elevato si era infatti raggiunto nel 2013 con 164.967 affari in corso; nel 2019 il numero è sceso a $101.073^{79}$, tornando al di sotto dei valori del $2005^{80}$. La durata dei procedimenti di primo grado nell'anno giudiziario 2018/2019 è sostanzialmente stabile, essendo passata da 229 a 228 giorni $^{81}$.

Gli uffici del giudice di pace hanno sicuramente tratto giovamento dalle passate depenalizzazioni ${ }^{82}$ e dalla trasformazione in illeciti civili di alcune fattispecie penali secondarie ma numericamente consistenti ${ }^{83}$. Non a caso, nel 2015 le notitiae criminis per ingiuria ammontavano a 37.504, mentre quelle per danneggiamento erano pari a 19.490, su un totale di notizie di reato soggettivamente qualificate di $624.436^{84}$. Oggi, l'ingiuria e le condotte-base di danneggiamento, che rientravano nella

78 Secondo VIGONI, Daniela, Ancora una riforma del giudizio abbreviato: l'inammissibilità per i delitti puniti con l'ergastolo, cit., p. 929, l'effetto è quello di procrastinare l'esecuzione della pena proprio per quei reati che destano il maggior allarme sociale, con un conseguente nocumento all'effettività della pena, intesa come un rapido accertamento di responsabilità ed una celere risposta sanzionatoria per soddisfare le «invocate richieste di giustizia della vittima e della collettività».

79 Fonte: MINISTERO DELLA GIUSTIZIA - DIPARTIMENTO DELL'ORGANIZZAZIONE GIUDIZIARIA, DEL PERSONALE E DEI SERVIZI - DIREZIONE GENERALE DI STATISTICA E ANALISI ORGANIZZATIVA, Monitoraggio della giustizia penale - anni 2003 - I trimestre 2020, cit.

Anche in questo caso, il dato sulle pendenze pare talvolta discostarsi dal rapporto tra procedimenti iscritti e definiti. Ad esempio, nel 2014 e 2017 i primi superavano i secondi. CORTE SUPREMA DI CASSAZIONE - MAMMONE, Giovanni, Relazione sull'amministrazione della giustizia nell'anno 2019, cit., p. 24. L'ultima depenalizzazione di carattere generale è stata realizzata con d.lgs. 15 gennaio 2016, n. 8.

83 Mediante d.lgs. 15 gennaio 2016, n. 7.

84 Fonte: ISTAT, Banca Dati I.Stat, in dati.istat.it (sito consultato l'8 luglio 2020). 
competenza del giudice di pace, sono divenute illeciti civili, mentre per la fattispecie ex art. 635 c.p., nella sua nuova formulazione più circoscritta, è competente il tribunale monocratico.

Tuttavia, la situazione potrebbe complicarsi a causa del d.lgs. n. $116 / 2017$, che, in esecuzione della legge delega n. 57/2016, ha riformato la magistratura onoraria, introducendo la nuova figura del giudice onorario di pace (g.o.p.) in sostituzione dei giudici di pace e dei giudici onorari di tribunale (g.o.t.). Le precedenti figure professionali resteranno in carica alcuni anni, per poi essere definitivamente sostituite dai g.o.p. ${ }^{85}$. La riforma conferma l'assenza di tutele assistenziali e previdenziali ${ }^{86}$, prevede un sostanziale decremento degli indennizzi ${ }^{87} \mathrm{e}$, almeno formalmente, un minore impegno quantitativo, con l'indicazione di un periodo massimo pari a due giorni alla settimana per assolvere alle proprie funzioni onorarie, che, a seconda delle maggiori o minori carenze di organico delle varie sedi, potrebbe rivelarsi un irragionevole limite alla produttività dei magistrati o, al contrario, una soglia meramente formale e disattesa nella prassi, idonea soltanto a giustificare l'esiguità dei predetti indennizzi ${ }^{88}$.

In generale, la riforma ha ridotto le prerogative dei giudici onorari e li ha indirizzati in modo massiccio all'impiego nell'ufficio per il processo dei tribunali ${ }^{89}$, nonostante sia nota la carenza di organico dei giudici di

85 Gli artt. 29-31 d.lgs. n. 116/2017 dettano la disciplina transitoria per i magistrati onorari nominati secondo le regole previgenti.

86 I contributi previdenziali sono a carico del magistrato onorario: v. art. 25 d.lgs. n. 116/2017.

87 Definisce le quote fisse di indennità per i g.o.p. «di consistenza oltraggiosa, perché di poco superiori ai 600 euro netti mensili» BRACCIALINI, Roberto, Magistratura onoraria: e adesso?, in www.questionegiustizia.it, 11 maggio 2020. Ad esse vanno poi aggiunte le quote variabili.

Il primo concorso per titoli volto a selezionare i giudici onorari di pace e i vice-procuratori onorari secondo la nuova normativa si è tenuto sulla base del bando pubblicato in Gazz. uff., Suppl. Ord. n. 1, 4 a Serie speciale, 13 febbraio 2018, n. 13.

89 V. art. 9 comma 3 d.lgs. n. 116/2017, che detta un'incompatibilità tra l'appartenenza all'ufficio per il processo e l'esercizio della giurisdizione civile e penale negli uffici del giudice di pace. Per approfondimenti, v. AGHINA, Ernesto, L'utilizzazione dei giudici onorari in tribunale dopo la riforma, in Giustizia insieme, 17 novembre 2018. 
pace $^{90}$. La novella, riguardando anche i magistrati onorari presso i tribunali, rischia pure di determinare conseguenze negative sulla produttività di questi ultimi uffici, considerando altresì la disciplina molto stringente sull'assegnazione di procedimenti penali di competenza del tribunale ai giudici non togati e sulla loro destinazione nei collegi ${ }^{91}$.

Considerato il ruolo indispensabile dei giudici di pace nel sistema giudiziario italiano - $\mathrm{i}$ quali, in àmbito penale, si occupano di reati minori che in mancanza graverebbero sui già oberati tribunali monocratici occorre introdurre efficaci correttivi ordinamentali per garantirne buone condizioni di lavoro e per favorire così non solo una celere definizione dei procedimenti, ma innanzitutto la loro indipendenza.

\section{Segue: le corti d'APpello.}

Per quanto riguarda la situazione delle corti d'appello, negli ultimi anni si registra un decremento dei processi in corso: $275.596 \mathrm{nel}$ 2017, 271.247 nel 2018 e 263.317 nel 2019. Il dato, tuttavia, conforta solo in parte: il valore del 2017 è il più alto degli ultimi quindici anni e, da inizio rilevazione, le pendenze sono più che raddoppiate (nel 2003, primo anno riportato, esse ammontavano a 130.395). In sostanza, l'attuale diminuzione pare inserirsi nell'andamento altalenante ma sostanzialmente stazionario dei tempi più recenti: dal 2004 al 2013 il valore è infatti costantemente aumentato, giungendo nel 2013 a 266.475 procedimenti, per poi assestarsi mediamente intorno ai 265.000 processi in corso, con periodici incrementi e flessioni che si bilanciano a vicenda negli anni ${ }^{92}$.

Tuttavia, salvo eccezioni, gli uffici di corte d'appello sono tra i più in difficoltà, come dimostra la durata media dei procedimenti, pari addirittura a 840 giorni nel 2018/2019: pur essendo in calo del 2,4\%

90 Intorno al 64\% secondo AGHINA, Ernesto, L'utilizzazione dei giudici onorari in tribunale dopo la riforma, cit.

91 Artt. 9 comma 4, 11 e 12 d.lgs. n. 116/2017.

92 Fonte: MINISTERO DELLA GIUSTIZIA - DIPARTIMENTO DELL'ORGANIZZAZIONE GIUDIZIARIA, DEL PERSONALE E DEI SERVIZI - DIREZIONE GENERALE DI STATISTICA E ANALISI ORGANIZZATIVA, Monitoraggio della giustizia penale - anni 2003 - I trimestre 2020, cit. 
rispetto all'anno giudiziario precedente, resta il valore più elevato tra tutte le fasi e i gradi del procedimento penale, superiore ai due anni previsti per il secondo grado dalla legge Pinto ${ }^{93}$.

Ad oggi non pare che i tempi processuali abbiano subìto sensibili modifiche a seguito dell'introduzione dell'obbligo di rinnovazione istruttoria in caso di appello del pubblico ministero contro sentenze di proscioglimento per motivi attinenti alla valutazione della prova dichiarativa ${ }^{94}$, previsione peraltro limitata dalla giurisprudenza alle prove decisive ${ }^{95}$.

Un istituto dal consistente potenziale deflativo è il concordato in appello ai sensi degli artt. 599-bis e 602 comma 1-bis c.p.p., reintrodotto dalla legge n. 103/2017, che però riceve ancora un'applicazione fin troppo limitata da parte degli operatori, anche a causa delle sue limitazioni oggettive ${ }^{96}$.

Tale situazione, in assenza di efficaci soluzioni correttive, risulterà ancor più critica quando entreranno a pieno regime dapprima

93 Fonte: CORTE SUPREMA DI CASSAZIONE - MAMMONE, Giovanni, Relazione sull'amministrazione della giustizia nell'anno 2019, cit., p. 24.

Anche il disposition time si assesta su valori simili: 835 giorni (v. supra, par. 2).

94 Obbligo introdotto dapprima in via giurisprudenziale (Cass., sez. un., 28 aprile 2016, n. 27620, Dasgupta, in Cass. pen., 2016, p. 3203 ss.; Cass., sez. un., 19 gennaio 2017, n. 18620, Patalano, in Cass. pen., 2017, p. 2666 ss.) per adeguarsi agli insegnamenti della Corte EDU (Corte eur. dir. uomo, sez. III, 5 luglio 2011, Dan c. Moldavia, in Arch. pen. - Riv. Web, 2012, n. 2; Corte eur. dir. uomo, sez. I, 29 giugno 2017, Lorefice c. Italia, in hudoc.echr.coe.int/ fre? $\left.{ }^{2}=001-175865\right)$ e poi in via legislativa con l'art. 603 comma 3-bis c.p.p., inserito dalla legge n. 103/2017.

95 Per questa lettura restrittiva dell'art. 603 comma 3-bis c.p.p., in linea con la giurisprudenza immediatamente anteriore all'inserimento di tale disposizione, v., ex multis, Cass., sez. un., 21 dicembre 2017, n. 14800, p.m. in proc. Troise, in Guida dir., 2018, n. 24, p. 68 ss.; Cass., sez. II, 3 luglio 2018, n. 39077 , in Guida dir., 2018, n. 38, p. 80. Secondo la più recente relazione sull'amministrazione della giustizia della Corte di cassazione, sarebbero stati segnalati «da più parti» dei rallentamenti a causa dell'obbligo di rinnovazione (CORTE SUPREMA DI CASSAZIONE - MAMMONE, Giovanni, Relazione sull'amministrazione della giustizia nell'anno 2019, cit., p. 38, che però, dopo aver riferito genericamente dette segnalazioni, non fornisce informazioni dettagliate). Sembra tuttavia che questi eventuali rallentamenti non abbiano inciso in modo rilevante sulle statistiche a livello nazionale.

96 CORTE SUPREMA DI CASSAZIONE - MAMMONE, Giovanni, Relazione sull'amministrazione della giustizia nell'anno 2019, cit., p. 38. 
la riforma della prescrizione del reato dettata dalla legge n. 103/2017che ha introdotto due ulteriori cause di sospensione in appello e in cassazione, entrambe della durata massima di un anno e sei mesi - e poi quella di cui alla legge n. $3 / 2019$, che detta una singolare causa di sospensione "permanente" 97 a partire dalla sentenza di primo grado o dal decreto di condanna e fino alla conclusione del giudizio con pronuncia irrevocabile ${ }^{98}$.

In appello - ma anche, in misure diverse, negli altri stati e gradi del procedimento - la prescrizione riveste concretamente un ruolo fondamentale per la sostenibilità del sistema, definendo una serie di procedimenti di caratura di solito non particolarmente elevata, divenuti ormai vetusti. I reati che il legislatore considera più gravi sono infatti imprescrittibili ${ }^{99}$ o presentano termini molto lunghi ${ }^{100}$.

In particolare, se è vero che la maggior parte delle dichiarazioni di prescrizione avviene in fase d'indagine (nel 2019 i provvedimenti di archiviazione per tale causa di estinzione del reato sono 43.745 su un

97 È improprio parlare in questo caso di sospensione, poiché la prescrizione cessa definitivamente di decorrere: per tutti, DE CARO, Agostino, La riforma della prescrizione e il complesso rapporto tra tempo, vicende della punizione e processo: le eccentriche soluzioni legislative e le nuove proiezioni processuali sulla prescrizione dell'azione e l'estinzione del processo, in Arch. pen. - Riv. Web, 2020, n. 1, p. 4 s.; MARANDOLA, Antonella, Prescrizione, effetti collaterali e rimedi, in Sist. pen., 23 luglio 2020; FERRUA, Paolo, La prescrizione del reato e l'insostenibile riforma "Bonafede", in Giur. it., 2020, p. 978.

La prima novella si applica ai reati commessi dal 3 agosto 2017, la seconda a quelli commessi dall'1 gennaio 2020. Tra l'altro, la nuova formulazione dell'art. 159 c.p. presenta diverse incongruenze: ad esempio, non si contemplano gli effetti della revoca del decreto penale in caso di opposizione, né quelli dell'annullamento delle pronunce di primo grado, che provocano una regressione a un momento precedente alla sospensione, non si prevedono termini massimi e di fase nelle impugnazioni: SPANGHER, Giorgio, Un confronto senza pregiudizi sulla prescrizione, in Giur. it., 2020, p. 973.

99 V. infatti l'art. 157 comma 8 c.p., secondo cui «la prescrizione non estingue i reati per i quali la legge prevede la pena dell'ergastolo, anche come effetto dell'applicazione di circostanze aggravanti».

${ }^{100}$ La prescrizione è raddoppiata per le fattispecie di cui all'art. 157 comma 6 c.p., mentre l'art. 160 c.p., che detta le cause di interruzione del corso della prescrizione, prevede un limite massimo al relativo incremento dei tempi, fatta eccezione per i delitti ex art. 51 commi 3-bis e 3-quater c.p.p. 
totale di 113.524 dichiarazioni di prescrizione) ${ }^{101}$, una considerevole percentuale è riscontrabile pure in appello: 29.725 nel 2019, pari al 26,18\%.

Le dichiarazioni di prescrizione in secondo grado sono in aumento dal 2012: da 13.726 nel 2011, pari all'11,38\% del totale ${ }^{102}$, sono passate nel 2012 a 18.592 (il $16,91 \%{ }^{103}$ ), per poi crescere di anno in anno a 21.521 (il 18,00\% ${ }^{104}$ ), 24.304 (il 18,62\% ${ }^{105}$ ), 24.326 (il 18,68\% ${ }^{106}$ ), 25.748 (il 18,81\% ${ }^{107}$ ), 28.185 (il 22,43\% ${ }^{108}$ ), 29.216 (il $24,16 \%{ }^{109}$ ) e 29.725 (il $26,18 \%{ }^{110}$ ). Vi è dunque una progressione sia in valore assoluto sia in percentuale rispetto al numero di procedimenti dichiarati prescritti in ogni stato e grado. L'aumento percentuale è comunque in parte dovuto alla generale e significativa contrazione delle pronunce di prescrizione

${ }^{101}$ Per i dati sulla prescrizione del reato contenuti nel presente paragrafo, v. MINISTERO DELLA GIUSTIZIA - DIPARTIMENTO DELL'ORGANIZZAZIONE GIUDIZIARIA, DEL PERSONALE E DEI SERVIZI - DIREZIONE GENERALE DI STATISTICA E ANALISI ORGANIZZATIVA PRESSO IL MINISTERO DELLA GIUSTIZIA (DG-STAT), Statistiche giudiziarie. Area penale, cit. Per i dati sulla prescrizione in cassazione, v. CORTE SUPREMA DI CASSAZIONE UFFICIO DI STATISTICA, La Cassazione penale - Annuario statistico 2019. Periodo 01/01/2019 - 31/12/2019, in www.cortedicassazione.it, 16 gennaio 2020. Le percentuali, approssimate alla seconda cifra decimale, sono state calcolate autonomamente aggregando tali statistiche.

${ }^{102}$ Il numero complessivo è 120.196 nelle fasi e nei gradi di merito, oltre a 404 procedimenti prescritti in cassazione, per un totale di 120.600 nel 2011.

103 Procedimenti totali definiti per prescrizione nel 2012: 109.944 (109.510 nelle fasi e nei gradi di merito).

${ }^{104}$ Procedimenti totali definiti per prescrizione nel 2013: 119.557 (119.119 nelle fasi e nei gradi di merito).

105 Procedimenti totali definiti per prescrizione nel 2014: 130.543 (129.613 nelle fasi e nei gradi di merito).

106 Procedimenti totali definiti per prescrizione nel 2015: 130.209 (129.531 nelle fasi e nei gradi di merito).

107 Procedimenti totali definiti per prescrizione nel 2016: 136.888 (136.120 nelle fasi e nei gradi di merito).

108 Procedimenti totali definiti per prescrizione nel 2017: 125.680 (125.020 nelle fasi e nei gradi di merito).

109 Procedimenti totali definiti per prescrizione nel 2018: 120.907 (120.261 nelle fasi e nei gradi di merito).

${ }^{110}$ Procedimenti totali definiti per prescrizione nel 2019: 113.524 (112.663 nelle fasi e nei gradi di merito). 
negli ultimi anni, ridottesi complessivamente da 136.888 nel 2016 a 113.524 nel 2019.

Sul totale dei procedimenti definiti in secondo grado, la percentuale di quelli conclusi con sentenza di non doversi procedere per prescrizione è elevata: nel 2011 erano il 17,34\%, nel 2012 il 19,51\% e, negli anni successivi fino al 2019 , il $21,52 \%$, il $23,46 \%$, il $24,05 \%$, il $23,44 \%$, il $25,76 \%$, il $25,39 \%$ e il $25,82 \%$. Da alcuni anni, un processo su quattro in appello termina dunque in tal modo.

Non è questa la sede per soffermarsi sulle finalità della prescrizione, correlate all'attenuarsi dell'interesse pubblico a punire e al graduale venir meno delle esigenze di rieducazione del reo in conseguenza dello scorrere del tempo ${ }^{111}$, nonché alla maggior difficoltà nel raccogliere prove e nel ricostruire i fatti a notevole distanza temporale dagli eventi ${ }^{112}$. Tuttavia, se è vero che, da un punto di vista teorico, lo scopo della prescrizione non è quello di garantire la ragionevole durata del processo ${ }^{113}$, sono innegabili le ricadute indirette della prima sulla seconda ${ }^{114}$.

111 V. ad esempio FIANDACA, Giovanni - MUSCO, Enzo, Diritto penale. Parte generale, $8^{\mathrm{a}}$ ed., Zanichelli, Bologna, 2019, p. 839. Sul «potere al reo di divenir migliore» col passare del tempo, v., già nel 1764, BECCARIA, Cesare, Dei delitti e delle pene (1764), edizione a cura di BURGIO, Alberto, $6^{\mathrm{a}}$ ed., Feltrinelli, Milano, 1998, p. 89.

${ }^{112}$ GATTA, Gian Luigi, Una riforma dirompente: stop alla prescrizione del reato nei giudizi di appello e di cassazione, in Dir. pen. cont., 21 gennaio 2019.

Quest'ultima finalità, il cui mancato perseguimento può ledere il diritto di difesa, permane anche in secondo grado, soprattutto a seguito dell'introduzione dell'art. 603 comma 3-bis c.p.p., non essendo più l'appello un giudizio di natura meramente cartolare.

113 Per tutti, GIOSTRA, Glauco, Prima lezione sulla giustizia penale, cit., p. 81 ss.; GIOSTRA, Glauco, Un giusto equilibrio dei tempi, sfida per la nuova prescrizione, in Sist. pen., 13 gennaio 2020.

${ }^{114}$ Nello stesso senso, si vis, PASCUCCI, Nicola, Azione penale e durata dei procedimenti in Italia e in Europa: alcune osservazioni “dati alla mano", cit., p. 33. Sul punto, v. anche MARANDOLA, Antonella, Prescrizione e processo: l'asistematicità dell'attuale disciplina, cit., p. 993; MAZZA, Oliviero, La riforma dei due orologi: la prescrizione fra miti populisti e realtà costituzionale, cit., secondo cui «la prescrizione non è in sé capace di garantire la ragionevole durata del processo, ma rappresenta la sanzione per i casi limite in cui comunque tale ragionevole durata è stata superata»; DE CARO, Agostino, Tempo, punizione e processo: le indubbie connessioni tra la ragion d'essere della prescrizione e la durata ragionevole del processo. La prospettiva dell'improcedibilità dell'azione, 
Al netto di ogni considerazione in merito alle predette novelle ${ }^{115}$, occorre innanzitutto fare i conti con la realtà: una sospensione "perpetua" della prescrizione a partire dalla pronuncia della sentenza di primo grado, senza alcuna riforma organica del diritto penale e processuale in grado di prevedere adeguate soluzioni compensative, è insostenibile per la giustizia italiana ${ }^{116}$. Essa determinerà senz'altro un allungamento della durata dei procedimenti, sia per il materiale incremento del carico giudiziario da valutare necessariamente nel merito (anche datato, con conseguenti difficoltà nell'accertamento), sia per l'assenza di termini che fungano da incentivo per l'autorità giudiziaria ${ }^{117}$ (in primis per $\mathrm{i}$ giudici di appello e di cassazione, ma anche per il pubblico ministero

in Sist. pen., 22 luglio 2020, il quale ritiene che la prescrizione del reato e la ragionevole durata del processo siano indiscutibilmente connesse e che alla prima non possa negarsi, in assenza di altre regole sul decorso del tempo, «una diretta, anche se parziale, incidenza» sulla seconda, benché la disciplina risulti «non soddisfacente, di retroguardia, limitata solo ad evitare gli arbitri più eclatanti»; ASSOCIAZIONE TRA GLI STUDIOSI DEL PROCESSO PENALE “GIAN DOMENICO PISAPIA”, Sulla proposta di modifica della disciplina della prescrizione, in Dir. pen. cont., 9 novembre 2018.

115 Sui dubbi di incostituzionalità della riforma del 2019, v., per tutti, ASSOCIAZIONE TRA GLI STUDIOSI DEL PROCESSO PENALE “GIAN DOMENICO PISAPIA", Sulla proposta di modifica della disciplina della prescrizione, cit. In tale presa di posizione, di poco anteriore all'approvazione definitiva della legge n. 3/2019, l'Associazione ha evidenziato la stretta correlazione tra la prescrizione e la ragionevole durata del processo, volta a tutelare non soltanto l'imputato, ma anche la persona offesa e la collettività, individuando un contrasto tra la ragionevole durata e la riforma in esame, ancor più palese nella parte in cui sospende in ogni caso la prescrizione dopo la pronuncia di primo grado, non distinguendo tra sentenza di assoluzione e di condanna; MAZZA, Oliviero, La riforma dei due orologi: la prescrizione fra miti populisti e realtà costituzionale, cit. V. altresì l'appello dell'Unione Camere Penali Italiane e di oltre centodieci professori di diritto costituzionale, penale e processuale penale, inviato al Capo dello Stato prima dell'approvazione della legge $n$. $3 / 2019$, in cui si denunciavano possibili vizi di incostituzionalità ex artt. 24, 27 commi 2 e 3, 111 comma 2 Cost. e 6 parr. 1 e 2 CEDU: AA.VV., Controriforma della prescrizione: l'appello dell'Accademia e dei Penalisti italiani al Presidente della Repubblica, in www.camerepenali.it, 19 dicembre 2018.

${ }^{116}$ Della medesima opinione è MONGILLO, Vincenzo, Essere e dover essere della prescrizione penale tra diritti fondamentali e neopunitivismo, cit., p. 1003.

117 Soprattutto per i reati di caratura medio-bassa, per i quali, non essendovi imputati sottoposti a custodia cautelare, non ci sono neppure i relativi termini massimi di durata come deterrenti. 
nelle indagini preliminari, per il giudice dell'udienza preliminare e per il giudice di primo grado, consapevoli di poter impiegare l'intera durata prescrizionale per indagini, udienza preliminare e primo grado ${ }^{118}$ ). Ciò accadrà spesso per quei reati di minor allarme sociale e privi di risonanza mediatica (l'attenzione dei mass media può essere infatti un altro pungolo per l'organo giudicante), ma comunque coinvolgenti interessi fondamentali per il singolo imputato, presunto innocente. Che il termine di prescrizione possa costituire un incentivo per l'autorità giudiziaria a procedere celermente è intuibile: una possibile concausa del maggiore disposition time presso il tribunale collegiale rispetto a quello monocratico ${ }^{119}$ può essere proprio rappresentata dalla presenza di termini prescrizionali più lunghi, oltre ovviamente a una particolare complessità delle questioni. Sarebbe fuorviante ritenere di compensare sic et simpliciter tali rilevanti controindicazioni con la previsione di un possibile mutamento nelle scelte difensive correlato al venir meno della possibilità di raggiungere la prescrizione del reato ${ }^{120}$. Tale osservazione parte da un dato qualitativo e statisticamente indimostrato, cioè la pretestuosità delle ragioni che sorreggono un'indefinita percentuale di appelli e di opzioni difensive. Essa non considera neppure che le scelte dilatorie funzionali a raggiungere la prescrizione non sono sempre così appetibili per l'imputato, producendo rilevanti effetti indesiderati: una dilatazione temporale del procedimento, pur non garantendo di per sé il raggiungimento della prescrizione, comporta di converso un prolungato carico di sofferenze per il medesimo, oltre a possibili problemi concreti

118 UNIONE CAMERE PENALI ITALIANE, Appello agli onorevoli Senatori e Deputati, al Presidente del Consiglio dei Ministri, al Ministro della Giustizia, in www.aipdp.it, 2 dicembre 2019.

119 V. supra, par. 2.

${ }^{120}$ Una parte della dottrina ritiene che il decorso della prescrizione dopo la sentenza di primo grado possa scoraggiare l'accesso ai riti premiali ed incentivare gli appelli dilatori: v., per tutti, GATTA, Gian Luigi, Audizione informale del Prof. Gian Luigi Gatta (Ordinario di Diritto penale nell'Università degli Studi di Milano, Direttore del Dipartimento di Scienze Giuridiche "C. Beccaria”) nell'ambito dell'esame del disegno di legge C. 1189 Governo "Misure per il contrasto dei reati contro la pubblica amministrazione e in materia di trasparenza dei partiti e movimenti politici”, Camera dei Deputati - Commissioni riunite Giustizia e Affari Costituzionali, 12 novembre 2018, p. 9 s. 
in altri àmbiti della vita, ad esempio sul lavoro ${ }^{121}$. Non vi è ragione di ritenere che il carattere dilatorio di alcune scelte difensive rivesta un peso maggiore nella durata dei procedimenti rispetto al summenzionato venir meno dell'effetto acceleratorio dei termini prescrizionali sull'operato dell'autorità giudiziaria, altro dato difficilmente quantificabile da un punto di vista numerico ${ }^{122}$. Inoltre, un appello pretestuoso non necessita in genere né di un esame particolarmente complesso né, ove presentato dal difensore dell'imputato, di alcuna rinnovazione probatoria ai sensi dell'art. 603 comma 3-bis c.p.p.: l'impatto complessivo di possibili appelli dilatori dovrebbe quindi risultare ridotto.

Interessante è anche l'analisi dei dati distrettuali sulla prescrizione, molto eterogenei tra loro ${ }^{123}$.

${ }^{121}$ Il procedimento penale comparirebbe infatti per anni nel certificato dei carichi pendenti, richiesto da numerosi datori di lavoro.

Si rinuncerebbe poi all'eventuale estinzione del reato spesso conseguente ai riti premiali e, qualora non si raggiungesse la prescrizione e si venisse condannati, interverrebbe con molto ritardo l'estinzione del reato successiva alla sospensione condizionale della pena.

122 Secondo FLICK, Giovanni Maria, Dall'oblio alla memoria: o viceversa? Divagazioni sulla prescrizione, cit., p. 901, è difficile comprendere se la "responsabilità" della lunghezza dei procedimenti sia maggiormente ascrivibile agli avvocati oppure ai magistrati e alle carenze organizzative, considerati altresì i dati statistici sulla durata, molto eterogenei tra i vari uffici giudiziari. Di conseguenza, prosegue l'A., «è infondato e ingiustificato il clichè ampiamente ed artatamente diffuso della responsabilità prevalente dell'imputato - soprattutto se dotato di mezzi economici - e del suo difensore nell'allungare a dismisura i tempi di prescrizione con le proprie iniziative», a fortiori in quanto queste ultime sono state man mano inquadrate tra le cause di sospensione della prescrizione. V. altresì BRONZO, Pasquale, La prescrizione del reato sotto l'incubo della ragionevole durata, in Sist. pen., 29 luglio 2020, secondo cui è ormai chiaro che l'irragionevole durata dei processi «non dipende, se non in casi eccezionali, dalle chicane difensive»; MONGILLO, Vincenzo, Essere e dover essere della prescrizione penale tra diritti fondamentali e neopunitivismo, cit., p. 1003.

${ }^{123}$ Per le statistiche seguenti, v. MINISTERO DELLA GIUSTIZIA - DIPARTIMENTO DELL'ORGANIZZAZIONE GIUDIZIARIA, DEL PERSONALE E DEI SERVIZI - DIREZIONE GENERALE DI STATISTICA E ANALISI ORGANIZZATIVA PRESSO IL MINISTERO DELLA GIUSTIZIA (DG-STAT), Statistiche giudiziarie. Area penale, cit. 
Nel 2019, su 15.794 processi definiti presso la Corte d'appello di Roma ${ }^{124}$, se ne concludono ben 7.589 con sentenza di non doversi procedere per prescrizione, cioè il $48,05 \%$. Nello stesso periodo, la Corte d'appello di Napoli definisce 9.854 processi, di cui 2.964 per prescrizione, cioè il 30,08\%; quella di Bologna ne termina complessivamente 8.440, di cui 2.984 per prescrizione, cioè il 35,36\%; la Corte d'appello di Firenze ne definisce in tal modo 2.380 su 7.395 (il 32,18\%) e quella di Venezia 2.041 su 5.240 (il 38,95\%). In totale, le prescrizioni dichiarate in secondo grado nei distretti di Roma, Napoli, Bologna, Firenze e Venezia sono 17.958, cioè il 60,41\% di quelle pronunciate in appello a livello nazionale nel 2019, benché i processi definiti da queste Corti siano 38.518 su 115.130 (il 33,46\%): cinque sedi su ventisei accumulano quindi sei sentenze di prescrizione su dieci, pur definendo soltanto tre processi su dieci. Il 25,53\% delle prescrizioni in secondo grado, poi, sono pronunciate nel distretto di Roma; tuttavia, solo il 13,72\% degli appelli conclusi nel nostro Paese è definito da questa Corte d'appello. Ciò non significa che le sedi maggiori siano necessariamente destinate all'inefficienza: nel 2019, presso la Corte d'appello di Milano, le sentenze di estinzione del reato per prescrizione sono 394 su 8.872, cioè soltanto il 4,44\%, mentre a Torino sono 1.696 su 8.387 , cioè il $20,22 \%{ }^{125}$.

Le differenze a livello locale sono evidenti, nonostante l'uniforme disciplina a livello nazionale: se ne può desumere che il problema non stia tanto nella normativa della prescrizione in sé, come configurata dalla (seppur problematica) legge n. 251/2005, ancor oggi operante per i reati commessi fino al 3 agosto $2017^{126}$, ma in un'organizzazione poco efficiente di alcuni uffici, per carenza di personale o per altri

${ }^{124}$ I dati che seguono ricomprendono anche i valori relativi alla Corte d'assise d'appello e alla sezione minorile, i cui numeri sono tuttavia pressoché trascurabili.

${ }^{125}$ Il dato, in poco tempo, è aumentato per la Corte d'appello di Bologna, che nel 2016 contava soltanto il $18,6 \%$ di prescrizioni, ed è diminuito per quella di Torino, che nel 2016 ne annoverava addirittura il 40,33\%.

${ }^{126}$ Gli effetti diretti delle novelle del 2017 e del 2019 si potranno osservare gradualmente a distanza di quattro/otto anni, cioè quando inizieranno a maturare i relativi termini di prescrizione, considerate anche le interruzioni e le sospensioni. Per alcuni delitti con termini prescrizionali più lunghi, i tempi saranno maggiori. Prima di quel momento, possono valutarsi soltanto 
fattori ${ }^{127}$. La sospensione "perpetua" della prescrizione in appello non farà che accrescere il divario tra gli uffici meglio organizzati e quelli peggio organizzati, con la conseguenza di provocare, in questi ultimi, processi dai tempi estremamente dilatati ${ }^{128}$. In assenza di correttivi idonei, l'alternativa a questa incontrollata dilatazione temporale sarebbe ugualmente inquietante: le corti, ancor più oberate di lavoro e mosse dall'intento di velocizzare il processo, potrebbero essere indotte a dar vita, con frequenza sempre maggiore, a prassi perverse più o meno nascoste volte a svilire il contraddittorio in nome dell'efficienza, snaturando l'appello e trasformandolo in una sorta di "ratifica cartolare" del primo grado ${ }^{129}$.

possibili variazioni nei comportamenti del giudice, del pubblico ministero e della difesa.

${ }^{127}$ Alle medesime conclusioni, partendo dalla disomogeneità dei dati territoriali relativi al 2016, si giungeva in PASCUCCI, Nicola, Azione penale e durata dei procedimenti in Italia e in Europa: alcune osservazioni "dati alla mano", cit., p. 35 s. V. altresì FLICK, Giovanni Maria, Dall'oblio alla memoria: o viceversa? Divagazioni sulla prescrizione, cit., p. 901.

${ }^{128}$ In dottrina si è parlato, in modo colorito ma efficace, di «ergastolo processuale», che lede la ragionevole durata, la presunzione d'innocenza e il diritto alla prova: così FILIPPI, Leonardo, "Se un processo diventa infinito": il commento di Leonardo Filippi, in www.unionesarda.it, 2 gennaio 2019.

${ }^{129}$ Già oggi vengono talvolta alla luce prassi devianti irrispettose del contraddittorio, sintomo di una concezione dell'appello non allineata ai valori costituzionali. Presso la Corte d'appello di Venezia - che, non a caso, è attualmente una delle corti d'appello più sovraccaricate di lavoro - sono state recentemente inviate per errore alcune sentenze ai difensori prima dell'udienza di discussione: tutte di rigetto, con tanto di determinazione delle spese in favore della parte civile e termine per la motivazione (anziché motivazione contestuale). Tale episodio, avvenuto a seguito di un disguido tecnico della cancelleria, ha portato alla luce la prassi nascosta di decidere l'esito del processo già prima dell'udienza, redigendo perfino la pronuncia. Questa prassi patologica è stata addirittura giustificata dal presidente di sezione, sulla base delle sue ricadute positive in termini di efficienza e della possibilità per il collegio di modificare l'esito a seguito della discussione: v. MUSCO, Simona, Sentenze copia-incolla. Bonafede spedisce gli ispettori a Venezia, in Il Dubbio, 16 luglio 2020, p. 5. L'Unione Camere Penali Italiane ha fin da sùbito stigmatizzato l'evento: UNIONE CAMERE PENALI ITALIANE, Lo svilimento del giudizio di appello. L'Unione con le Camere Penali del Veneto, in www.camerepenali.it, 15 luglio 2020. 


\section{Segue: la Corte di cassazione.}

In Corte di cassazione, i procedimenti pendenti sono in calo: da 35.984 nel 2015 sono passati, di anno in anno, a 30.354, 30.236, 24.609 e $23.579^{130}$. Dal 2016, i processi definiti superano quelli iscritti. Sono in calo dal 2016 anche i tempi di durata media, calcolati dall'iscrizione in cancelleria all'udienza: nel 2015 erano di 219 giorni, per poi passare a 240 nel 2016 e successivamente decrescere a 200, 180 e $167^{131}$. L'incidenza della prescrizione del reato resta trascurabile: 678 procedimenti così definiti nel 2015 (1,2\% sul totale dei processi conclusi in sede di legittimità), 768 nel 2016 (1,4\%), 660 nel 2017 (1,2\%), 646 nel 2018 $(1,1 \%)$ e 861 nel $2019(1,7 \%)^{132}$. Si tratta spesso di processi che giungono già estinti all'attenzione del giudice nomofilattico, necessitando solo della formale dichiarazione ${ }^{133}$.

Per comprendere le conseguenze sull'organo di legittimità della legge n. 3/2019, non occorre tuttavia soffermarsi sulle esigue percentuali di prescrizione davanti alla Suprema Corte, ma è necessario considerare i potenziali ricorsi contro le decisioni in appello per reati che, secondo la previgente disciplina, si sarebbero prescritti. Se non assistita da idonei correttivi, la legge n. 3/2019 determinerà dunque conseguenze preoccupanti anche nel grado di legittimità, con un aumento stimato di circa 25.000 procedimenti all'anno, pari al 50\% dell'attuale carico di lavoro ${ }^{134}$.

${ }^{130}$ Fonte: MINISTERO DELLA GIUSTIZIA - DIPARTIMENTO DELL'ORGANIZZAZIONE GIUDIZIARIA, DEL PERSONALE E DEI SERVIZI - DIREZIONE GENERALE DI STATISTICA E ANALISI ORGANIZZATIVA, Monitoraggio della giustizia penale - anni 2003 - I trimestre 2020, cit.

${ }^{131}$ Fonte: CORTE SUPREMA DI CASSAZIONE - UFFICIO DI STATISTICA, La Cassazione penale - Annuario statistico 2019. Periodo 01/01/2019 31/12/2019, cit., p. 2, 27.

${ }^{132}$ Fonte: CORTE SUPREMA DI CASSAZIONE - UFFICIO DI STATISTICA, La Cassazione penale - Annuario statistico 2019. Periodo 01/01/2019 31/12/2019, cit., p. 30.

${ }^{133}$ In tal senso, Giovanni Canzio, intervistato da Giovanni Negri su Il Sole 24 Ore, 7 novembre 2018, p. 8.

${ }^{134}$ CORTE SUPREMA DI CASSAZIONE - MAMMONE, Giovanni, Relazione sull'amministrazione della giustizia nell'anno 2019, cit., p. 29 s. 
Anche i dati attuali sull'efficienza processuale, all'apparenza molto positivi, devono essere però correttamente valutati.

La Cassazione dispone infatti di un improprio mezzo deflativo, che, per l'ampiezza con cui viene inteso, desta condivisibili perplessità ${ }^{135}$ : la declaratoria d'inammissibilità del ricorso. I procedimenti dichiarati inammissibili nel 2019 sono addirittura 34.850 su 51.420, pari al 67,8\%, di cui 20.823 provenienti dalla settima sezione e 14.027 dalle altre ${ }^{136}$.

Si ha la sensazione che la Suprema Corte si serva talvolta di tale strumento per evitare di dichiarare prescritto il reato, variando caso per caso il perimetro della "manifesta infondatezza"137. L'infondatezza "manifesta" è infatti una causa d'inammissibilità dai contorni molto sfumati, essendo praticamente impossibile stabilire a priori il confine tra un ricorso infondato e uno "manifestamente" infondato. Vi è quindi il pericolo, in assenza di un maggiore self restraint della Corte, di frustrare l'effettività dell'art. 111 comma 7 Cost. e la funzione nomofilattica della medesima in nome della speditezza processuale, innalzato indebitamente a valore prioritario ${ }^{138}$.

La predetta riforma della prescrizione, aumentando il carico di lavoro della Suprema Corte, potrebbe aggravare la situazione anche da questo punto di vista, inducendo quest'ultima a restringere ulteriormente le maglie del giudizio d'inammissibilità per manifesta infondatezza.

135 ALONZI, Fabio - MANNA, Adelmo (a cura di), Considerazioni sui "numeri" della Cassazione, in Dir. pen. cont., 21 giugno 2019, p. 5 ss.

${ }^{136}$ Fonte: CORTE SUPREMA DI CASSAZIONE - UFFICIO DI STATISTICA, La Cassazione penale - Annuario statistico 2019. Periodo 01/01/2019 31/12/2019, cit., p. $14 \mathrm{~s}$.

137 MACCHIA, Alberto, Prescrizione, Taricco e dintorni: spunti a margine di un sistema da riformare, cit., p. 9; ALONZI, Fabio - MANNA, Adelmo (a cura di), Considerazioni sui "numeri" della Cassazione, cit., p. 7. Similmente, FLICK, Giovanni Maria, Dall'oblio alla memoria: o viceversa? Divagazioni sulla prescrizione, cit., p. 908.

138 ALONZI, Fabio - MANNA, Adelmo (a cura di), Considerazioni sui "numeri" della Cassazione, cit., p. 6 s. Rileva criticità nella sottile distinzione tra manifesta infondatezza e semplice infondatezza, dovendosi evitare una «eccessiva discrezionalità nella declaratoria di inammissibilità» MAZZA, Oliviero, La Corte assediata e il garantismo efficiente (note a margine della Carta di Napoli), in Proc. pen. giust., 2014, n. 5, p. 4. 
Le modifiche all'art. 610 c.p.p. ad opera della legge n. 103/2017 hanno poi favorito le più celeri dichiarazioni d'inammissibilità de plano: i procedimenti definiti «senza formalità» sono passati dallo $0,5 \%$ del 2017 al 9,2\% del $2019^{139}$. Un'altra preoccupante prassi è quella di invitare i difensori a "riportarsi ai motivi", sintomo di una malintesa nozione di efficienza processuale, incentivata al punto da far erroneamente ritenere ultronee le garanzie del contraddittorio e dell'oralità ${ }^{140}$.

\section{Cosa fare? Considerazioni finali e PROSPettive di RIForma.}

Tralasciando ogni considerazione sul diritto di difesa e sul contraddittorio nella formazione della prova, i quali meritano un'autonoma ed approfondita disamina che non può fondarsi su basi statistiche e misurabili1 ${ }^{141}$, ci si soffermerà sull'efficienza e sulla durata dei procedimenti. Il quadro generale presenta criticità, ma la situazione non può comunque definirsi emergenziale e sussistono pure segnali positivi, come il numero decrescente delle nuove notizie di reato e la diminuzione delle pendenze presso alcuni organi. Particolari difficoltà sono tuttavia riscontrabili presso il tribunale e, soprattutto, presso la corte d'appello.

Si è visto che problemi ulteriori scaturiscono da recenti modifiche legislative, adottate spesso in un'ottica repressiva senza considerare attentamente le ripercussioni sotto i profili dell'efficienza processuale e dei rapporti tra quest'ultima e le altre garanzie del giusto processo. Né si prefigurano all'orizzonte scenari più ottimistici, anche alla luce del nuovo disegno di legge delega per la riforma del procedimento penale, da poco presentato in Parlamento ${ }^{142}$.

139 Fonte: CORTE SUPREMA DI CASSAZIONE - UFFICIO DI STATISTICA, La Cassazione penale - Annuario statistico 2019. Periodo 01/01/2019 31/12/2019, cit., p. 11. V. anche ALONZI, Fabio - MANNA, Adelmo (a cura di), Considerazioni sui "numeri" della Cassazione, cit., p. 4, 6.

${ }^{140}$ ALONZI, Fabio - MANNA, Adelmo (a cura di), Considerazioni sui "numeri" della Cassazione, cit., p. 5.

${ }^{141}$ Sul punto, si rinvia integralmente alle riflessioni già formulate in PASCUCCI, Nicola, Azione penale e durata dei procedimenti in Italia e in Europa: alcune osservazioni "dati alla mano", cit., p. 36 ss.

${ }^{142}$ Disegno di legge C. 2435, intitolato «Delega al Governo per l'efficienza del processo penale e disposizioni per la celere definizione dei procedimenti 
Non è questa la sede per soffermarsi analiticamente su ogni aspetto da riformare. Si vogliono semplicemente tratteggiare, nei loro aspetti essenziali e alla luce della situazione concreta sopra delineata, alcune modifiche ottenibili in tempi relativamente brevi, per implementare la speditezza della giustizia penale italiana senza sacrificare le altre garanzie del giusto processo.

Gli interventi normativi prospettati riguardano la disciplina penale e soprattutto processuale penale, lasciando sullo sfondo sia le proposte di natura ordinamentale ${ }^{143}$ e risarcitoria, sia quelle di carattere organizzativo, forse ancor più rilevanti: è del resto opinione diffusa che buona parte delle disfunzioni della giustizia penale riguardino appunto il reclutamento, la gestione e l'organizzazione del personale ${ }^{144}$. Il completamento degli organici di magistrati e personale amministrativo rappresenta una condicio sine qua non per il buon andamento della giustizia ${ }^{145}$, a fortiori se si considera che a fine 2019 risulta una consistente scopertura nelle piante

giudiziari pendenti presso le corti d'appello», presentato alla Camera dei Deputati il 13 marzo 2020 dal Ministro della Giustizia, il cui testo è disponibile sul sito istituzionale www.camera.it. Per un commento, si rinvia a GIALUZ, Mitja - DELLA TORRE, Jacopo, Il progetto governativo di riforma della giustizia penale approda alla camera: per avere processi rapidi (e giusti) serve un cambio di passo, in Sist. pen., 2020, n. 4, p. 145 ss. Si condividono le critiche espresse da FERRUA, Paolo, La prescrizione del reato e l'insostenibile riforma "Bonafede", cit., p. 978 ss., secondo cui tali modifiche non sarebbero idonee ad implementare l'efficienza processuale e si porrebbero pure in contrasto col sistema accusatorio, facendo ulteriormente arretrare il baricentro del processo verso la fase delle indagini ( $\mathrm{v}$. ad esempio la variazione della regola di giudizio nell'udienza preliminare, che rischia di instillare nel giudice del dibattimento un pregiudizio sulla colpevolezza dell'imputato, nonché l'ampliamento dell'art. 190-bis c.p.p. nell'ipotesi di variazione del collegio).

${ }^{143}$ Compresa la ricorrente proposta di separazione tra le carriere del giudice e del pubblico ministero, su cui non è possibile soffermarsi in questa sede e che necessiterebbe di un'articolata riflessione.

${ }^{144}$ FERRUA, Paolo, Il 'giusto processo', cit., p. 108 s.; BRONZO, Pasquale, La prescrizione del reato sotto l'incubo della ragionevole durata, cit.; MAZZA, Oliviero, La riforma dei due orologi: la prescrizione fra miti populisti e realtà costituzionale, cit. V. altresì, per alcune possibili soluzioni a problemi organizzativi, SCALFATI, Adolfo, Processo penale, "ragionevole durata" e recenti proposte, cit., p. 1311.

145 Per tutti, CERESA GASTALDO, Massimo, Dall'obbligatorietà dell'azione penale alla selezione politica dei processi, in Dir. pen. cont. - Riv. trim., 2011, p. 24. 
organiche, pari al 9,83\% per la magistratura e al $22,82 \%$ per il personale amministrativo ${ }^{146}$. Sarebbe poi importante ampliare numericamente la magistratura onoraria e procedere a una sua riforma organica, in grado di garantirle condizioni economiche, assistenziali e previdenziali adeguate ${ }^{147}$.

Occorre innanzitutto un'ulteriore depenalizzazione di carattere generale - seguita eventualmente dalla trasformazione di alcuni illeciti penali in illeciti civili - per restituire al diritto penale il suo fisiologico carattere di extrema ratio ${ }^{148}$, restringendone così i confini in favore della responsabilità amministrativa e civile; nell'àmbito del perimetro così rimodellato, sarebbe anche opportuno semplificare le fattispecie, riducendo il numero di reati ${ }^{149}$. Sembrano inoltre opportuni la diminuzione dei limiti edittali di molte fattispecie (in modo da favorire l'accesso ad istituti quali la messa alla prova e la particolare tenuità) e l'estensione della procedibilità a querela ${ }^{150}$, che dilaterebbe pure la portata pratica

${ }^{146}$ I dati sono attinti da CORTE SUPREMA DI CASSAZIONE - MAMMONE, Giovanni, Relazione sull'amministrazione della giustizia nell'anno 2019, cit., p. 30, 32. La relazione preannuncia nuovi concorsi per assumere 5.000 persone.

${ }^{147}$ Ritiene ad esempio che debba essere fatto un uso più ampio dei c.d. v.p.o. nelle procure, per implementarne la produttività, CERESA GASTALDO, Massimo, Dall'obbligatorietà dell'azione penale alla selezione politica dei processi, cit., p. 24.

${ }^{148}$ A favore di una «coraggiosa depenalizzazione» è MONGILLO, Vincenzo, Essere e dover essere della prescrizione penale tra diritti fondamentali e neopunitivismo, in Giur. it., 2020, p. 1007. Definisce «timide» le più recenti depenalizzazioni STORTONI, Luigi, Il diritto penale sotto il segno dell'efficienza del sistema, in Riv. it. dir. proc. pen., 2019, p. 381. Analizzando la legge delega n. 67/2014, sulla base della quale sono stati emanati i d.lgs. n. 7/2016 e n. 8/2016 (ultimi interventi generali volti a ridurre l'area dell'illiceità penale), riteneva necessario più coraggio e razionalità SCALFATI, Adolfo, La debole convergenza di scopi nella deflazione promossa dalla l. n. 67 del 2014, in Proc. pen. giust., 2014, n. 5, p. 142 s., il quale proponeva ad esempio una selezione fondata sui beni giuridici, facendo arretrare la tutela penale ove non fosse più percepita come socialmente necessaria.

149 È noto che il diritto penale sia ormai divenuto ipertrofico: v., per tutti, GIOSTRA, Glauco, Prima lezione sulla giustizia penale, cit., p. 80; MONGILLO, Vincenzo, Essere e dover essere della prescrizione penale tra diritti fondamentali e neopunitivismo, cit., p. 1007.

150 CERESA GASTALDO, Massimo, Dall'obbligatorietà dell'azione penale alla selezione politica dei processi, cit., p. 24; KOSTORIS, Roberto E., Per un'obbligatorietà temperata dell'azione penale, in Riv. dir. proc., 2007, p. 881. 
dell'art. 162-ter c.p., da poco introdotto ${ }^{151}$. Per potenziare la capacità deflativa della depenalizzazione e della rimodulazione sanzionatoria, dovrebbe prestarsi un'attenzione particolare, ove possibile, ai reati più diffusi, pur senza tralasciare le altre fattispecie ${ }^{152}$. Il furto è ad esempio il delitto più denunciato (e raggiunge altresì, in presenza di circostanze aggravanti, limiti edittali estremamente elevati, da rimeditare ${ }^{153}$ ): si registrano 1.192 .592 notitiae criminis nel 2018, pari al 50,28\% delle denunce totali per delitti ${ }^{154}$; considerando invece i soli procedimenti con "autore noto" (rectius con iscrizione di un indagato nel registro delle notizie di reato) nel 2018, le denunce per furto sono $70.255 \mathrm{su}$ 573.533 , cioè il $12,25 \%$. Tale reato è numericamente consistente anche sotto il profilo delle sentenze definitive di condanna (33.217 persone condannate per furto nel 2017, pari al 15,99\% dei soggetti condannati per delitti). Dopo i furti, i delitti che impegnano maggiormente la giustizia penale sono le minacce ${ }^{155}$, le truffe e le frodi informatiche ${ }^{156}$,

${ }^{151}$ Non tutti sono d'accordo con l'implementazione di istituti come la particolare tenuità, la messa alla prova, la procedibilità a querela e le condotte riparatorie, considerati come un allontanamento dalla finalità accertativa del processo, attribuita costituzionalmente alla giurisdizione, e rappresentativi di un «modello di "privatizzazione"» della giustizia, che si limita a un'attività «di "ratifica" dell'accordo altrove compiuto»: così RICCIO, Giuseppe, La crisi della giustizia tra pressioni comunitarie e recessioni interne, in Arch. pen. - Riv. Web, 2019, n. 3, p. 14.

${ }^{152}$ Per i dati che seguono sulla prevalenza dei delitti in Italia, v. ISTAT, Banca Dati I.Stat, cit. Le percentuali sono state elaborate autonomamente sulla base delle summenzionate statistiche, con approssimazione alla seconda cifra decimale.

${ }^{153}$ L'eccessiva entità delle pene crea talvolta situazioni paradossali che intasano la giustizia fino al grado di legittimità, come è accaduto nel caso del furto di una melanzana, qualificato come aggravato ex art. 625 c.p. in quanto l'ortaggio, trovandosi in un campo, è per sua natura esposto alla pubblica fede. La fattispecie consumata non rientra neppure nei limiti edittali della particolare tenuità: per alcune considerazioni, v. GATTA, Gian Luigi, La Cassazione e il furto (tentato) di una melanzana: tra tenuità del fatto e patologie della giustizia penale, in Dir. pen. cont., 2018, n. 4, p. 183 ss.

${ }^{154}$ Le contravvenzioni non sono ricomprese nelle statistiche fornite dall'ISTAT.

$155 \mathrm{Nel} 2018$, le minacce sono il 3,16\% di tutte le notitiae criminis e il 7,92\% di quelle con "autore noto".

156 Pari al 7,97\% delle denunce totali e al 7,27\% di quelle con "autore noto" nel 2018. I condannati con sentenza irrevocabile per truffa ammontano inoltre al $2,88 \%$ del totale nel 2017. 
le lesioni dolose ${ }^{157}$ e i delitti in materia di sostanze stupefacenti ${ }^{158}$ : su di essi occorre in primis focalizzare l'attenzione per valutare eventuali interventi normativi.

L'estinzione del reato per condotte riparatorie ex art. 162-ter c.p., poco valorizzata nella prassi ${ }^{159}$, ha evidentemente bisogno di un supporto informativo, mediante l'introduzione di obblighi di avvertimento sia al momento dell'esercizio dell'azione penale sia prima dell'apertura del dibattimento.

Sarebbe opportuno estendere la portata della non punibilità per particolare tenuità del fatto ex art. 131-bis c.p. al fine di potenziarne l'efficacia deflativa ${ }^{160}$, introducendo ad esempio un comma 1-bis nell'art. 131-bis c.p. che elenchi specifiche fattispecie cui rendere applicabile l'istituto, ulteriori rispetto a quelle ricomprese nei limiti edittali del comma $1^{161}$. In relazione alla causa di improcedibilità per particolare tenuità dinanzi al giudice di pace ex art. 34 d.lgs. n. 274/2000, potrebbero abrogarsi le previsioni che la subordinano alla mancata opposizione della persona offesa o all'assenza, durante le indagini, di un interesse di quest'ultima alla prosecuzione del procedimento.

In relazione alla prescrizione del reato, si è già osservato come le recenti riforme, in assenza di idonee soluzioni compensative, rischino di provocare rilevanti riflessi negativi sulla durata dei procedimenti, che la nostra giustizia penale, già sovraccarica, non può permettersi. Questo istituto sostanziale è stato più volte modificato rendendone man mano

157 Pari al 2,76\% delle denunce totali e al 7,26\% di quelle con "autore noto" nel 2018. I condannati con sentenza irrevocabile per lesioni dolose sono inoltre il 3,85\% del totale nel 2017.

${ }^{158}$ Pari all'1,70\% delle denunce totali e al 6,87\% di quelle con "autore noto" nel 2018. I condannati con sentenza irrevocabile per delitti in materia di stupefacenti sono inoltre l'11,82\% del totale nel 2017.

${ }^{159}$ CORTE SUPREMA DI CASSAZIONE - MAMMONE, Giovanni, Relazione sull'amministrazione della giustizia nell'anno 2019, cit., p. 37.

${ }^{160}$ L'istituto è infatti utilizzato in modo crescente, ma si riscontra un «modesto impatto sul numero dei procedimenti sopravvenuti»: CORTE SUPREMA DI CASSAZIONE - MAMMONE, Giovanni, Relazione sull'amministrazione della giustizia nell'anno 2019, cit., p. 37.

${ }^{161}$ BORGNA, Paolo, Esercizio obbligatorio dell'azione penale nell'era della “pan-penalizzazione”, in www.questionegiustizia.it, 31 ottobre 2019. 
più complessa la fisionomia, con l'effetto - fin da prima delle novelle del 2017 e del 2019 - di stabilire termini minimi di prescrizione piuttosto lunghi in relazione a reati di scarso allarme sociale ${ }^{162}$. Sono state avanzate diverse ipotesi de iure condendo ${ }^{163}$ : nessuna di esse è però venuta alla luce. Sarebbe utopistico, tenuto conto della storia recente, tentare ampie e articolate riforme della prescrizione in tempi brevi: sul tema il legislatore è costante nel privilegiare interpolazioni della trama normativa esistente anziché azioni più impegnative. Tuttavia il tempo stringe: per scongiurare gli effetti negativi che produrranno le novelle del 2017 e del 2019 una volta entrate "a regime", sarebbe forse più agevole e veloce ripristinare in toto una disciplina già sperimentata in passato e perciò prevedibile negli effetti, coi correttivi strettamente necessari per adeguarsi ai dettami della Corte costituzionale $^{164}$. La soluzione più lineare finora storicamente adottata resta quella del legislatore del 1930, che suddivideva le fattispecie in fasce sulla

${ }^{162}$ Ci si riferisce alla legge n. 251/2005.

${ }^{163}$ V., per tutti, GATTA, Gian Luigi - GIOSTRA, Glauco, Sul dibattito in tema di prescrizione del reato e sul vero problema della giustizia penale: la lentezza del processo, in Sist. pen., 11 febbraio 2020; GIOSTRA, Glauco, Il problema della prescrizione penale: aspetti processuali, in Giur. it., 2005, p. 2221 ss.; GIUNTA, Fausto - MICHELETTI, Dario, Tempori cedere. Prescrizione del reato e funzioni della pena nello scenario della ragionevole durata del processo, Giappichelli, Torino, 2003, p. 108 ss.; MAZZA, Oliviero, La riforma dei due orologi: la prescrizione fra miti populisti e realtà costituzionale, cit.; PULITANÒ, Domenico, Il nodo della prescrizione, in Dir. pen. cont. - Riv. trim., 2015, n. 1, p. 23 ss.; RICCIO, Giuseppe, La crisi della giustizia tra pressioni comunitarie e recessioni interne, cit., p. 17; VIGANÒ, Francesco, Riflessioni de lege lata e ferenda su prescrizione e tutela della ragionevole durata del processo, in Dir. pen. cont. - Riv. trim., 2013, n. 3, p. 18 ss. V. anche Indagine conoscitiva in merito all'esame delle proposte di legge C. 1174 Colletti, C. 1528 Mazziotti Di Celso e C. 2150 Ferranti, recanti «Modifiche al codice penale in materia di prescrizione dei reati», in Commissione II Giustizia - Resoconto stenografico - Indagine conoscitiva, seduta di mercoledì 19 novembre 2014, reperibile in documenti. camera.it, in cui il Prof. Glauco Giostra, il Prof. Tullio Padovani, l'Avv. Beniamino Migliucci (Presidente dell'Unione Camere Penali Italiane) e il Dott. Rodolfo Maria Sabelli (Presidente dell'Associazione Nazionale Magistrati) enunciano le loro posizioni in merito alle proposte di legge allora presentate in materia di prescrizione.

${ }^{164}$ Alcune disposizioni previgenti erano state infatti ritenute incostituzionali. Per evitare di reintrodurre norme illegittime, occorre tener presenti le passate pronunce della Consulta, come ad esempio Corte cost., sent. 31 maggio 1990, n. 275, in Gazz. uff., $1^{\text {a }}$ serie speciale, n. 23 del 6 giugno 1990, p. 13 
base dei limiti edittali, senza termini minimi né incrementi per tipologie di reato, i quali finiscono per creare sperequazioni tra le fattispecie. Una prescrizione dipendente dalla fascia edittale in cui è inserito il reato e non correlata sic et simpliciter al massimo di pena astrattamente previsto, come accade invece con la legge $n$. 251/2005, ha il pregio di limitare i legami tra riforme di parte speciale ${ }^{165}$ e prescrizione del reato ${ }^{166}$. In quest'ottica, l'opzione più immediata consisterebbe nel riportare le cause di sospensione e di interruzione al testo del 1989, adattato al nuovo codice di procedura penale ${ }^{167}$. Solo una volta ripristinata celermente la pregressa disciplina della prescrizione, evitando così le gravi conseguenze pratiche derivanti dalle leggi n. 103/2017 e soprattutto n. 3/2019, potrebbe discutersi serenamente di modifiche più ampie e impegnative.

Dal punto di vista processuale, si auspica l'introduzione di un vero e proprio processo penale telematico (p.p.t.) sulla falsariga di quello civile, evitando mortificazioni del contraddittorio e dell'immediatezza. Negli ultimi anni il legislatore pare invece indirizzarsi sulla via di una malintesa informatizzazione: allargare le maglie della partecipazione al dibattimento e dell'esame a distanza ex art. 146-bis c.p.p. ${ }^{168}$ non significa

ss., che aveva dichiarato l'incostituzionalità dell'originario art. 157 c.p. nella parte in cui non prevedeva la possibilità di rinunciare alla prescrizione.

${ }^{165}$ Evitando compulsivi ritocchi al rialzo delle sanzioni. Sull'«aumento stratosferico delle pene per impedire che un reato venga prescritto, come fa la Spazzacorrotti», cioè la legge n. 3/2019, v. FLICK, Giovanni Maria, Dall'oblio alla memoria: o viceversa? Divagazioni sulla prescrizione, cit., p. 905.

${ }^{166}$ Per questa ragione, considera preferibile il sistema originario del codice Rocco rispetto a quello della legge n. 251/2005 PULITANÒ, Domenico, Il nodo della prescrizione, cit., p. 23. L'A. ritiene necessario tornare al sistema «per fasce di gravità di tipi di reato», essendo «più organico, più maneggevole nelle applicazioni, meno instabile, meglio controllabile». Il medesimo osserva che nemmeno il sistema del 1930 era totalmente indipendente dalle scelte del legislatore di parte speciale, ma, «affidando al legislatore di parte generale la determinazione di termini di prescrizione ritenuti congrui con riguardo alla natura e gravità dei reati delle diverse fasce, assicura l'autonomia assiologica delle scelte in materia di prescrizione». Propone di ripristinare una «differenziazione dei termini per fasce di gravità dei reati» MONGILLO, Vincenzo, Essere e dover essere della prescrizione penale tra diritti fondamentali e neopunitivismo, cit., p. 1006.

${ }^{167}$ L'art. 239 disp. att. c.p.p. aveva infatti sostituito l'art. 160 comma 2 c.p.

168 Come ha fatto la legge n. 103/2017. 
implementare il processo penale telematico, ma affievolire i suddetti principî, poiché una partecipazione da remoto - e a fortiori un esame non sono mai equiparabili alle correlative attività de $v i s u^{169}$. Le differenze sono molte: oltre ai frequenti problemi nella qualità dell'audio e del video e alle difficoltà nell'instaurare e nel mantenere il collegamento, è comunque pressoché impossibile cogliere, durante un esame a distanza, tutte le intonazioni dell'eloquio e le componenti del linguaggio non verbale del soggetto. Questo tipo di informatizzazione tradisce una scarsa considerazione per il contraddittorio, l'oralità e l'immediatezza. Purtroppo, l'attuale pandemia da Covid-19 ha indotto il legislatore a consentire in via eccezionale un uso ancora più ampio di tali modalità ${ }^{170}$. D'altro canto, la crisi epidemiologica è stata anche l'occasione per "muovere i primi passi" nel processo telematico correttamente inteso, implementando l'uso degli strumenti tecnologici per il deposito di istanze, documenti e memorie difensive ex art. 415-bis c.p.p. ${ }^{171}$. Tuttavia, il percorso per l'attuazione del processo penale telematico è appena iniziato e sarà necessario un maggiore impegno non solo del legislatore, ma anche degli operatori giuridici, talvolta riluttanti ai cambiamenti ${ }^{172}$.

${ }^{169}$ Come osserva anche l'ASSOCIAZIONE TRA GLI STUDIOSI DEL PROCESSO PENALE, Prime indicazioni per una riforma sistematica del processo penale, in Arch. pen. - Riv. Web, 2019, n. 1, p. 13.

${ }^{170}$ L'art. 83 comma 12-bis decreto legge 17 marzo 2020, n. 18, convertito con modificazioni dalla legge 24 aprile 2020, n. 27, ha previsto la possibilità di celebrare le udienze da remoto, purché - afferma la legge - siano salvaguardati «il contraddittorio e l'effettiva partecipazione delle parti».

${ }^{171}$ V. l'art. 83 comma 12-quater.1 decreto legge 17 marzo 2020, n. 18, convertito con modificazioni dalla legge 24 aprile 2020, n. 27, come ulteriormente modificato dall'art. 3 comma 2 lett. $f$, decreto legge 30 aprile 2020, n. 28 . Il primo ufficio giudiziario abilitato agli invii telematici ai sensi delle predette disposizioni è stata la Procura della Repubblica presso il Tribunale di Napoli, tramite decreto del Ministro della Giustizia 9 giugno 2020, pubblicato in Gazz. uff., 11 giugno 2020, n. 147.

Pure diversi uffici giudiziari si sono adoperati in questo senso, approvando protocolli per il periodo di emergenza che consentono invii tramite pec.

Oggi si è anche diffusa la possibilità, presso alcuni uffici, di ricevere telematicamente le copie di determinati atti previo pagamento da remoto dei diritti, mediante il sistema PagoPA.

${ }^{172}$ Un esempio di questa ritrosia è l'atteggiamento della giurisprudenza penale nei confronti della posta elettronica certificata. Benché il d.p.r. 11 febbraio 
Altre soluzioni per decongestionare la giustizia penale riguardano i riti speciali ${ }^{173}$ : oltre alla necessità di ripristinare la precedente disciplina sull'accesso al giudizio abbreviato per i reati puniti con l'ergastolo, sarebbe opportuno rimodulare i limiti edittali di pena ex art. 168-bis comma 1 c.p. al fine di ampliare l'accesso al probation. Per rendere più appetibile quest'ultimo procedimento, si potrebbe prevedere la cancellazione dal casellario dell'ordinanza di ammissione e della sentenza di estinzione del reato dopo dieci anni, limitando l'impossibilità di una seconda richiesta al medesimo lasso temporale. Anche nel patteggiamento occorrerebbe un innalzamento dei limiti edittali di pena per l'accesso al rito ${ }^{174}$, valutando altresì l'opportunità di circoscrivere la portata degli artt. 444 commi 1-bis e 1-ter c.p.p. ${ }^{175}$. Del resto, negli ordinamenti accusatori anglosassoni il patteggiamento è uno strumento molto diffuso di definizione del processo ${ }^{176}$. Potrebbe pure prendersi in esame, come recentemente prospettato ${ }^{177}$,

2005, n. 68 la equipari alla raccomandata con ricevuta di ritorno, la Suprema Corte ritiene ad esempio inammissibile l'impugnazione proposta mediante pec, in quanto non contemplata dall'art. 583 c.p.p., le cui modalità di presentazione sono considerate tassative: v., ex multis, Cass., sez. III, 13 aprile 2018, n. 38411, in Banca Dati DeJure; Cass., sez. VI, 5 dicembre 2017, n. 55444, in Banca Dati DeJure; Cass., sez. V, 5 marzo 2015, n. 24332, in Banca Dati DeJure.

${ }^{173}$ Secondo FLICK, Giovanni Maria, Dall'oblio alla memoria: o viceversa? Divagazioni sulla prescrizione, cit., p. 904 s., sarebbe addirittura necessaria una «revisione $a b$ imis di tutto il sistema dei procedimenti speciali».

${ }^{174}$ L'art. 4 comma 1 lett. a n. 1 del predetto disegno di legge delega C. 2435 , presentato alla Camera dei Deputati il 13 marzo 2020 dal Ministro della Giustizia, prevede un incremento da cinque ad otto anni.

175 Il d.d.l. C. 2435, al contrario, prescrive un aumento delle ipotesi derogatorie, relativo ai casi in cui la pena è compresa da cinque ad otto anni (art. 4 comma 1 lett. $a$ n. 2).

${ }^{176}$ Secondo GRANDE, Elisabetta, Perché la prescrizione non crea problemi negli Usa?, in www.questionegiustizia.it, 31 gennaio 2019, la maggioranza dei processi statunitensi, con punte del 99\%, è definita mediante patteggiamento (plea bargain). L'A., tuttavia, critica aspramente tale prassi, poiché «segna il definitivo abbandono della ricerca di una verità, quale che sia». In ogni caso, la riforma sopra prospettata non condurrebbe il sistema verso simili eccessi, ma incrementerebbe in modo ragionevole l'utilizzo di tale istituto.

177 V. il primo dei c.d. "32 punti” per la riforma del processo penale (reperibili in calce a CONSIGLIO DELLE CAMERE PENALI, Lettera Unione Camere Penali, 
l'estensione dell'oblazione ai delitti puniti con pena pecuniaria o con pena alternativa, previa valutazione dell'impatto complessivo della modifica ${ }^{178}$.

Le suddette riforme dei riti speciali rivitalizzerebbero in parte anche la funzione dell'udienza preliminare, che altrimenti, considerata attualmente la sua scarsa efficacia di "filtro" 179 e l'inevitabile dilatazione temporale che comporta, rischia di produrre più effetti indesiderati che benefici ${ }^{180}$. Rivitalizzazione che potrebbe essere corroborata da una «cura dimagrante», attraverso l'ampliamento dei reati per cui si procede con citazione diretta a giudizio, la semplificazione della motivazione della sentenza di non luogo a procedere e l'abolizione dell'appello contro tale pronuncia ${ }^{181}$.

In secondo grado, parte della dottrina propone di ridurre il potere d'appello del pubblico ministero contro le sentenze di proscioglimento, non potendo intendersi il principio di parità tra le parti come specularità tra i loro rispettivi poteri ed essendo anzi fisiologica un'asimmetria in favore dell'imputato ${ }^{182}$. Per scongiurare il pericolo di una pronuncia

in Arch. pen. - Riv. Web, 2019, n. 1), poi però non riproposto nel summenzionato d.d.1. C. 2435.

178 Similmente, ASSOCIAZIONE TRA GLI STUDIOSI DEL PROCESSO PENALE, Documento del consiglio direttivo. Prime osservazioni sui trentadue punti della bozza di disegno di legge delega per la riforma del processo penale, in Arch. pen. Riv. Web, 2019, n. 1, p. 1.

${ }^{179}$ CORTE SUPREMA DI CASSAZIONE - MAMMONE, Giovanni, Relazione sull'amministrazione della giustizia nell'anno 2019, cit., p. 25.

${ }^{180}$ Ritengono addirittura che vada abolita DANIELE, Marcello, L'abolizione dell'udienza preliminare per rilanciare il sistema accusatorio, in Sist. pen., 2020, n. 1, p. 131 ss.; GIALUZ, Mitja - DELLA TORRE, Jacopo, Il progetto governativo di riforma della giustizia penale approda alla camera: per avere processi rapidi (e giusti) serve un cambio di passo, cit., p. 160 s., 200.

${ }^{181}$ Detta «cura dimagrante» è prospettata da AMODIO, Ennio, Riforme urgenti per il recupero della celerità processuale, in Dir. pen. proc., 2010, p. 1272, il quale prospetta altresì la totale sottrazione della sentenza di non luogo a procedere al regime delle impugnazioni. Quest'ultima proposta non pare però di semplice e rapido accoglimento, implicando - come afferma lo stesso A. una revisione costituzionale.

182 SCALFATI, Adolfo, Fluidificare il procedimento in Cassazione: proposte concrete e non rivoluzionarie, in Dir. pen. proc., 2015, p. 133. V. altresì FERRUA, Paolo, Il 'giusto processo', cit., p. 237 ss., secondo cui il radicale divieto di appellare le sentenze di proscioglimento dovrebbe inserirsi in 
d'incostituzionalità, occorrerebbe tuttavia preservare l'appellabilità delle sentenze proscioglitive per i reati più gravi ${ }^{183}$. Tale differenziazione tra fattispecie, seppur opinabile a causa della disparità che creerebbe tra di esse $^{184}$, pare tuttavia necessitata alla luce delle posizioni espresse dalla Consulta, intervenuta sul tema nel $2007^{185}$.

Sarebbe inoltre auspicabile incentivare il concordato in appello ${ }^{186}$, utile istituto deflativo reintrodotto dalla legge n. 103/2017 dopo essere stato abrogato nel $2008^{187}$, il quale, pur non presentando finalità premiali ${ }^{188}$, è stato indebitamente equiparato al patteggiamento allargato sotto il profilo

una più complessa rivisitazione delle impugnazioni, volta a perseguire la ragionevole durata del processo ed a ricalibrare le facoltà dell'imputato e della parte civile. Anche in assenza di una riforma più generale, l'introduzione del divieto de quo non potrebbe però ritenersi costituzionalmente illegittima.

${ }^{183}$ Ipotizza di ridurre l'appellabilità dei proscioglimenti da parte del p.m., in particolare «nei processi per reati meno gravi», SCALFATI, Adolfo, Fluidificare il procedimento in Cassazione: proposte concrete e non rivoluzionarie, cit., p. 133.

${ }^{184}$ Dello stesso avviso è FERRUA, Paolo, Il 'giusto processo', cit., p. 241. Sarebbe infatti molto meno irragionevole vietare al p.m. di appellare ogni sentenza di proscioglimento senza distinzione tra i reati, ma la soluzione, già adottata in passato, è stata ritenuta illegittima da Corte cost., sent. 7 febbraio 2007, n. 26, in Cass. pen., 2007, p. 1883 ss.

${ }^{185}$ Corte cost., sent. 7 febbraio 2007, n. 26, cit. La legge n. 46/2006 aveva già eliminato tale potere d'appello in relazione a tutti i reati, ma la Corte l'ha ripristinato, dichiarando illegittimo in parte qua l'art. 593 c.p.p. riformato. La Consulta ha ritenuto censurabile la previsione anche per il fatto di essere «generalizzata», cioè non «riferita a talune categorie di reati», ma «estesa indistintamente a tutti i processi».

${ }^{186}$ Il cui utilizzo è definito «inferiore alle attese» da CORTE SUPREMA DI CASSAZIONE - MAMMONE, Giovanni, Relazione sull'amministrazione della giustizia nell'anno 2019 , cit., p. 38.

${ }^{187}$ Mediante decreto legge n. 92/2008, convertito con modifiche in legge n. $125 / 2008$.

${ }^{188}$ V., ex multis, SPANGHER, Giorgio - MARANDOLA, Antonella, Concordato in appello: basta equivoci, in ilpenalista.it, 21 agosto 2017, p. 3. Il relazione all'omologo istituto abrogato nel 2008, CATALANO, Elena Maria, L'accordo sui motivi di appello, Giuffrè, Milano, 2001, p. 112. Per ulteriori riferimenti bibliografici, v., si vis, PASCUCCI, Nicola, Il ritorno del concordato sui motivi di appello, tra esigenze processuali e timori di malfunzionamento, in Dir. pen. cont., 2017, n. 11, p. 36, 42. 
delle esclusioni oggettive ${ }^{189}$. L'abrogazione dell'art. 599-bis comma 2 c.p.p. sarebbe quindi opportuna non solo per rivitalizzare l'istituto e favorirne così l'effetto deflativo, ma anche per evitare indebite sovrapposizioni concettuali tra patteggiamento e concordato.

Si tratta di rivisitazioni della disciplina sostanziale e processuale che parrebbero utili anche per limitare di riflesso il carico di lavoro del giudice nomofilattico, riducendo il numero di processi senza restringere le maglie della ricorribilità in cassazione ${ }^{190}$.

\section{Bibliografia}

AA.VV. Controriforma della prescrizione: l'appello dell'Accademia e dei Penalisti italiani al Presidente della Repubblica. Disponibile in: www.camerepenali.it/cat/9615/ controriforma_della_prescrizione_l'appello_dell'accademia_e_dei_penalisti_ italiani_al_presidente_della_repubblica.html, 19 dicembre 2018. Accesso in: 26 luglio 2020 .

AGHINA, Ernesto. L'utilizzazione dei giudici onorari in tribunale dopo la riforma. Giustizia insieme, 17 novembre 2018.

ALONZI, Fabio - MANNA, Adelmo (a cura di). Considerazioni sui "numeri" della Cassazione. Diritto penale contemporaneo, 21 giugno 2019.

AMODIO, Ennio. Giusto processo, procès équitable e fair trial: la riscoperta del giusnaturalismo processuale in Europa. Rivista italiana di diritto e procedura penale, 2003, p. 93 ss.

189 Sul punto, v. le osservazioni di BARGIS, Marta, I ritocchi alle modifiche in tema di impugnazioni nel testo del d.d.l. n. 2798 approvato dalla camera dei deputati, in Dir. pen. cont., 19 ottobre 2015, p. 5, formulate durante l'iter di approvazione della legge n. 103/2017.

${ }^{190}$ Nel tempo sono state elaborate diverse proposte: v., ad esempio, la c.d. "Carta di Napoli", le cui soluzioni, poi in parte recepite dal legislatore (v. art. 613 comma 1 c.p.p.), miravano altresì a ridurre la legittimazione e il novero dei provvedimenti ricorribili: ASSOCIAZIONE TRA GLI STUDIOSI DEL PROCESSO PENALE, La carta di Napoli. Per una riforma urgente del giudizio penale di cassazione, in camerepenali.it (consultato il 25 luglio 2020). V. altresì MAZZA, Oliviero, La Corte assediata e il garantismo efficiente (note a margine della Carta di Napoli), cit., p. 1 ss.; SCALFATI, Adolfo, Fluidificare il procedimento in Cassazione: proposte concrete e non rivoluzionarie, cit., p. 129 ss. 
AMODIO, Ennio. La procedura penale dal rito inquisitorio al giusto processo. Cassazione penale, 2003, p. 1419 ss.

AMODIO, Ennio. Ragionevole durata del processo, abuse of process e nuove esigenze di tutela dell'imputato. Diritto penale e processo, 2003, p. 797 ss.

AMODIO, Ennio. Riforme urgenti per il recupero della celerità processuale. Diritto penale e processo, 2010, p. 1269 ss.

ASSOCIAZIONE TRA GLI STUDIOSI DEL PROCESSO PENALE. Documento del consiglio direttivo. Prime osservazioni sui trentadue punti della bozza di disegno di legge delega per la riforma del processo penale. Archivio penale - Rivista Web, 2019, n. 1.

ASSOCIAZIONE TRA GLI STUDIOSI DEL PROCESSO PENALE "GIAN DOMENICO PISAPIA”. Sulla proposta di modifica della disciplina della prescrizione. Diritto penale contemporaneo, 9 novembre 2018.

ASSOCIAZIONE TRA GLI STUDIOSI DEL PROCESSO PENALE. La carta di Napoli. Per una riforma urgente del giudizio penale di cassazione. Disponibile in: camerepenali.it/public/file/Documenti/La\%20Carta\%20di\%20Napoli.pdf. Accesso in: 25 luglio 2020.

ASSOCIAZIONE TRA GLI STUDIOSI DEL PROCESSO PENALE. Prime indicazioni per una riforma sistematica del processo penale. Archivio penale - Rivista Web, 2019, n. 1.

BARGIS, Marta. I ritocchi alle modifiche in tema di impugnazioni nel testo del d.d.1. n. 2798 approvato dalla camera dei deputati. Diritto penale contemporaneo, 19 ottobre 2015 .

BECCARIA, Cesare. Dei delitti e delle pene (1764). Edizione a cura di BURGIO, Alberto, 6a ed., Milano: Feltrinelli, 1998.

BORGNA, Paolo. Esercizio obbligatorio dell'azione penale nell'era della "panpenalizzazione". Disponibile in: www.questionegiustizia.it/articolo/ esercizio-obbligatorio-dell-azione-penale-nell-era-della-ldquopanpenalizzazionerdquo_31-10-2019.php, 31 ottobre 2019. Accesso in: 4 agosto 2020.

BRACCIALINI, Roberto. Magistratura onoraria: e adesso? Disponibile in: www. questionegiustizia.it/articolo/magistratura-onoraria-e-adesso_11-05-2020.php, 11 maggio 2020. Accesso in: 27 luglio 2020.

BRONZO, Pasquale. La prescrizione del reato sotto l'incubo della ragionevole durata. Sistema penale, 29 luglio 2020. 
BRUTI LIBERATI, Edmondo. Audizione - Senato della Repubblica, $2^{a}$ Commissione, 12 febbraio 2019, Esame DDL n. 925 in materia di giudizio abbreviato. Disponibile in: www.senato.it/application/xmanager/projects/leg18/attachments/documento_ evento_procedura_commissione/files/000/001/207/DOTT._BRUTI_LIBERATI. pdf. Accesso in: 27 luglio 2020.

BUZZELLI, Silvia. § 10-15. In: BUZZELLI, Silvia - CASIRAGHI, Roberta - CASSIBBA, Fabio - CONCOLINO, Paola - PRESSACCO, Luca, Art. 6. Diritto a un equo processo. In: UBERTIS, Giulio - VIGANÒ, Francesco (a cura di), Corte di Strasburgo e giustizia penale, Torino: Giappichelli, 2016, p. 143 ss.

CAPRIOLI, Francesco. Abuso del diritto di difesa e nullità inoffensive. Cassazione penale, 2012, p. 2444 ss.

CATALANO, Elena Maria. L'accordo sui motivi di appello. Milano: Giuffrè, 2001.

CERESA GASTALDO, Massimo. Dall'obbligatorietà dell'azione penale alla selezione politica dei processi. Diritto penale contemporaneo - Rivista trimestrale, 2011, n. 1 , p. 21 ss.

CONSIGLIO DELLE CAMERE PENALI. Lettera Unione Camere Penali. Archivio penale - Rivista Web, 2019, n. 1.

CONSO, Giovanni. Introduzione. In: BARGIS, Marta (a cura di), Compendio di procedura penale. $9^{\mathrm{a}}$ ed., Milano: CEDAM, 2018, p. LXXXV ss.

CONTI, Carlotta. La messa alla prova tra le due Corti: aporie o nuovi paradigmi? Diritto penale e processo, 2018, p. 666 ss.

CORTE SUPREMA DI CASSAZIONE - MAMMONE. Giovanni. Relazione sull'amministrazione della giustizia nell'anno 2019. Disponibile in: www. cortedicassazione.it/cassazione-resources/resources/cms/documents/20190125_ RelazioneAG2018.pdf, 31 gennaio 2020. Accesso in: 28 giugno 2019.

CORTE SUPREMA DI CASSAZIONE - UFFICIO DI STATISTICA. La Cassazione penale - Annuario statistico 2019. Periodo 01/01/2019-31/12/2019. Disponibile in: http://www.cortedicassazione.it/cassazione-resources/resources/cms/ documents/La_Cassazione_penale_-_Annuario_statistico_2019.pdf, 16 gennaio 2020. Accesso in: 27 luglio 2020.

DANIELE, Marcello. L'abolizione dell'udienza preliminare per rilanciare il sistema accusatorio. Sistema penale, 2020, n. 1, p. 131 ss.

DE CARO, Agostino. La riforma della prescrizione e il complesso rapporto tra tempo, vicende della punizione e processo: le eccentriche soluzioni legislative e 
le nuove proiezioni processuali sulla prescrizione dell'azione e l'estinzione del processo. Archivio penale - Rivista Web, 2020, n. 1.

DE CARO, Agostino. Le ambigue linee di politica penale dell'attuale legislatore: giudizio abbreviato e reati puniti con la pena dell'ergastolo. Diritto penale e processo, 2018, p. 1627 ss.

DE CARO, Agostino. Tempo, punizione e processo: le indubbie connessioni tra la ragion d'essere della prescrizione e la durata ragionevole del processo. La prospettiva dell'improcedibilità dell'azione. Sistema penale, 22 luglio 2020.

DOLCINI, Emilio. La pena ai tempi del diritto penale illiberale. Diritto penale contemporaneo, 22 maggio 2019.

FERRUA, Paolo. Il 'giusto processo'. 3ª ed., Bologna: Zanichelli, 2012.

FERRUA, Paolo. Il sacrificio dell'oralità nel nome della ragionevole durata: i gratuiti suggerimenti della Corte costituzionale al legislatore. Archivio penale Rivista Web, 2019, n. 2.

FERRUA, Paolo. La prescrizione del reato e l'insostenibile riforma "Bonafede". Giurisprudenza italiana, 2020, p. 978 ss.

FERRUA, Paolo. La ragionevole durata del processo tra Costituzione e Convenzione europea. Disponibile in: www.questionegiustizia.it/rivista/articolo/la-ragionevoledurata-del-processo-tra-costituzione-e-convenzione-europea_422.php. Accesso in: 27 luglio 2020.

FIANDACA, Giovanni - MUSCO, Enzo. Diritto penale. Parte generale. $8^{\mathrm{a}}$ ed., Bologna: Zanichelli, 2019.

FILIPPI, Leonardo. "Se un processo diventa infinito": il commento di Leonardo Filippi. Disponibile in: www.unionesarda.it/articolo/news-sardegna/cagliari/2019/01/02/ se-un-processo-diventa-infinito-il-commento-di-leonardo-filippi-136-817369. html, 2 gennaio 2019. Accesso in: 27 luglio 2020.

FLICK, Giovanni Maria. Dall'oblio alla memoria: o viceversa? Divagazioni sulla prescrizione. Cassazione penale, 2020, p. 894 ss.

GARUTI, Giulio. Proposte per la ricostruzione sistematica del processo accusatorio: la fonte costituzionale. Archivio penale - Rivista Web, 2017, n. 3.

GATTA, Gian Luigi. Audizione informale del Prof. Gian Luigi Gatta (Ordinario di Diritto penale nell'Università degli Studi di Milano, Direttore del Dipartimento di Scienze Giuridiche “C. Beccaria) nell'ambito dell'esame del disegno di legge C. 1189 Governo "Misure per il contrasto dei reati contro la pubblica amministrazione 
e in materia di trasparenza dei partiti e movimenti politici”, Camera dei Deputati Commissioni riunite Giustizia e Affari Costituzionali. Disponibile in: www. camera.it/application/xmanager/projects/leg18/attachments/upload_file_ doc_acquisiti/pdfs/000/000/461/Prof._Gatta.pdf, 12 novembre 2018. Accesso in: 27 luglio 2020.

GATTA, Gian Luigi. La Cassazione e il furto (tentato) di una melanzana: tra tenuità del fatto e patologie della giustizia penale. Diritto penale contemporaneo, 2018, n. 4, p. 183 ss.

GATTA, Gian Luigi. Una riforma dirompente: stop alla prescrizione del reato nei giudizi di appello e di cassazione. Diritto penale contemporaneo, 21 gennaio 2019.

GATTA, Gian Luigi - GIOSTRA, Glauco. Sul dibattito in tema di prescrizione del reato e sul vero problema della giustizia penale: la lentezza del processo. Sistema penale, 11 febbraio 2020 .

GIALUZ, Mitja - DELLA TORRE, Jacopo. Il progetto governativo di riforma della giustizia penale approda alla camera: per avere processi rapidi (e giusti) serve un cambio di passo. Sistema penale, 2020, n. 4, p. 145 ss.

GIOSTRA, Glauco. Il problema della prescrizione penale: aspetti processuali. Giurisprudenza italiana, 2005, p. 2221 ss.

GIOSTRA, Glauco. Prima lezione sulla giustizia penale. Bari-Roma: Laterza, 2020.

GIOSTRA, Glauco. Un giusto equilibrio dei tempi, sfida per la nuova prescrizione. Sistema penale, 13 gennaio 2020.

GIUNTA, Fausto - MICHELETTI, Dario. Tempori cedere. Prescrizione del reato e funzioni della pena nello scenario della ragionevole durata del processo. Torino: Giappichelli, 2003.

GRANDE, Elisabetta. Perché la prescrizione non crea problemi negli Usa? Disponibile in: www.questionegiustizia.it/articolo/perche-la-prescrizione-non-crea-probleminegli-usa_31-01-2019.php, 31 gennaio 2019. Accesso in: 27 luglio 2020.

GREVI, Vittorio. Alla ricerca di un processo penale «giusto». Itinerari e prospettive. Milano: Giuffrè, 2000.

GREVI, Vittorio. Il principio della «ragionevole durata» come garanzia oggettiva del «giusto processo» penale. Cassazione penale, 2003, p. 3204 ss.

GUALTIERI, Piero. Durata ragionevole del processo e persona offesa. Diritto penale e processo, 2012, p. 1008 ss. 
ISTAT. Banca Dati I.Stat. Disponibile in: dati.istat.it/Index.aspx?DataSetCode=dccv_ delittips. Accesso in: 8 luglio 2020.

KOSTORIS, Roberto E. Con il nuovo «patteggiamento allargato» il rischio di una gigantesca negoziazione. Guida al diritto, 2003, n. 25, p. 9 s.

KOSTORIS, Roberto E. La ragionevole durata del processo nella Convenzione europea dei diritti dell'uomo e nell'art. 111 Cost. In: KOSTORIS, Roberto E. (a cura di), La ragionevole durata del processo. Garanzie ed efficienza della giustizia penale. Torino: Giappichelli, 2005, p. 3 ss.

KOSTORIS, Roberto E. Per un'obbligatorietà temperata dell'azione penale. Rivista di diritto processuale, 2007, p. 875 ss.

LAVARINI, Barbara. La ragionevole durata del processo come garanzia soggettiva. La legislazione penale, 31 dicembre 2019.

MACCHIA, Alberto. Prescrizione, Taricco e dintorni: spunti a margine di un sistema da riformare. Questione giustizia, 2017, n. 1, p. 9 ss.

MARANDOLA, Antonella. La riforma del giudizio abbreviato: prime questioni applicative ed esegetiche della legge n. 33 del 2019. Studium iuris, 2019, p. 1428 s.

MARANDOLA, Antonella. Prescrizione, effetti collaterali e rimedi. Sistema penale, 23 luglio 2020.

MARANDOLA, Antonella. Prescrizione e processo: l'asistematicità dell'attuale disciplina. Giurisprudenza italiana, 2020, p. 987 ss.

MARZADURI, Enrico. In: CANZIO, Giovanni - MARZADURI, Enrico - SILVESTRI, Giovanni, Preclusioni processuali e ragionevole durata del processo. Criminalia, 2008, p. 242 ss.

MAZZA, Oliviero. La Corte assediata e il garantismo efficiente (note a margine della Carta di Napoli). Processo penale e giustizia, 2014, n. 5, p. 1 ss.

MAZZA, Oliviero. La riforma dei due orologi: la prescrizione fra miti populisti e realtà costituzionale. Sistema penale, 21 gennaio 2020.

MINISTERO DELLA GIUSTIZIA - DIPARTIMENTO DELL'ORGANIZZAZIONE GIUDIZIARIA, DEL PERSONALE E DEI SERVIZI - DIREZIONE GENERALE DI STATISTICA E ANALISI ORGANIZZATIVA (DG-STAT). Statistiche giudiziarie. Area penale. Disponibile in: webstat.giustizia.it/StatisticheGiudiziarie/penale/ Area\%20penale.aspx. Accesso in: 8 luglio 2020. 
MINISTERO DELLA GIUSTIZIA - DIPARTIMENTO DELL'ORGANIZZAZIONE GIUDIZIARIA, DEL PERSONALE E DEI SERVIZI - DIREZIONE GENERALE DI STATISTICA E ANALISI ORGANIZZATIVA. Monitoraggio della giustizia penale - anni 2003 - I trimestre 2020. Disponibile in: www.giustizia.it/giustizia/it/mg_1_14_1. page? contentId=SST1288006\&previsiousPage=mg_1_14, 7 luglio 2020. Accesso in: 22 luglio 2020.

MINISTERO DELLA GIUSTIZIA - DIREZIONE GENERALE DI STATISTICA E ANALISI ORGANIZZATIVA (DG-STAT). La durata dei procedimenti civili. I principali indicatori a confronto. Anni 2012-2019. Disponibile in: webstat.giustizia. it/Analisi\%20e\%20ricerche/La\%20durata\%20dei\%20procedimenti\%20civili.pdf. Accesso in: 8 luglio 2020.

MONGILLO, Vincenzo. Essere e dover essere della prescrizione penale tra diritti fondamentali e neopunitivismo. Giurisprudenza italiana, 2020, p. 996 ss.

MUSCO, Simona, Sentenze copia-incolla. Bonafede spedisce gli ispettori a Venezia. Il Dubbio, 16 luglio 2020, p. 5.

NACAR, Barbara. I termini e la ragionevole durata del processo penale. Torino: Giappichelli, 2012.

NAPPI, Aniello. Prescrizione e ragionevole durata del processo. Giustizia insieme, 23 marzo 2020.

ORLANDI, Renzo. Procedimenti speciali. In: BARGIS, Marta (a cura di), Compendio di procedura penale. $9^{\mathrm{a}}$ ed., Milano: CEDAM, 2018, p. 639 ss.

PASCUCCI, Nicola. Azione penale e durata dei procedimenti in Italia e in Europa: alcune osservazioni “dati alla mano”. Cultura giuridica e diritto vivente, 2019.

PASCUCCI, Nicola. Il ritorno del concordato sui motivi di appello, tra esigenze processuali e timori di malfunzionamento. Diritto penale contemporaneo, 2017 , n. 11, p. 31 ss.

PILLONI, Raffaele. Giustizia penale negoziata e divieto di giudizio abbreviato per i delitti puniti con l'ergastolo. Archivio penale - Rivista Web, 2020, n. 1.

PREZIOSI, Stefano. Ergastolo e paradigma punitivo nel fuoco del giudizio abbreviato: linee di intersezione fra diritto e processo penale. Diritto penale $e$ processo, 2020, p. 245 ss.

PULITANÒ, Domenico. Il nodo della prescrizione. Diritto penale contemporaneo Rivista trimestrale, 2015, n. 1, p. 20 ss. 
RICCIO, Giuseppe. La crisi della giustizia tra pressioni comunitarie e recessioni interne. Archivio penale - Rivista Web, 2019, n. 3.

RICCIO, Giuseppe. Note sulla ragionevole durata nel processo penale. Cassazione penale, 2011, p. 4524 ss.

SCALFATI, Adolfo. Fluidificare il procedimento in Cassazione: proposte concrete e non rivoluzionarie. Diritto penale e processo, 2015, p. 129 ss.

SCALFATI, Adolfo. La debole convergenza di scopi nella deflazione promossa dalla 1. n. 67 del 2014. Processo penale e giustizia, 2014, n. 5, p. 141 ss.

SCALFATI, Adolfo. Processo penale, "ragionevole durata" e recenti proposte. Cassazione penale, 2015, p. 1309 ss.

SIRACUSANO, Fabrizio. La durata ragionevole del processo quale "metodo" della giurisdizione. Diritto penale e processo, 2003, p. 757 ss.

SPANGHER, Giorgio. Considerazioni sul processo "criminale" italiano. Torino: Giappichelli, 2015.

SPANGHER, Giorgio - MARANDOLA, Antonella. Concordato in appello: basta equivoci. Ilpenalista.it, 21 agosto 2017.

SPANGHER, Giorgio. Un confronto senza pregiudizi sulla prescrizione. Giurisprudenza italiana, 2020, p. 971 ss.

SPANGHER, Giorgio. Esclusi dall'abbreviato i reati puniti con l'ergastolo (1. n. 33 del 2019). Il processo, 2019, n. 2, p. 489 ss.

STORTONI, Luigi. Il diritto penale sotto il segno dell'efficienza del sistema. Rivista italiana di diritto e procedura penale, 2019, p. 379 ss.

TONINI, Paolo. Disciplina della prova e durata ragionevole del processo penale. Cassazione penale, 2004, p. 332 ss.

UBERTIS, Giulio. Azione penale, contraddittorio e durata ragionevole del processo. Rivista italiana di diritto e procedura penale, 2005, p. 130 ss.

UNIONE CAMERE PENALI ITALIANE. Appello agli onorevoli Senatori e Deputati, al Presidente del Consiglio dei Ministri, al Ministro della Giustizia. Disponibile in: www.aipdp.it/allegato_news/167_2019_12_02_Documento_Appello_Ingiustizia_ infinita.pdf, 2 dicembre 2019. Accesso in: 27 luglio 2020.

UNIONE CAMERE PENALI ITALIANE. Lo svilimento del giudizio di appello. L'Unione con le Camere Penali del Veneto. Disponibile in: www.camerepenali.it/ 
cat/10571/lo_svilimento_del_giudizio_di_appello_l'unione_con_le_camere_ penali_del_veneto.html, 15 luglio 2020. Accesso in: 27 luglio 2020.

VALIANI, Teresa (a cura di). Ergastolo, stop all'abbreviato. Intervista al prof. Glauco Giostra. Giustizia insieme, 5 aprile 2019.

VIGANÒ, Francesco. Riflessioni de lege lata e ferenda su prescrizione e tutela della ragionevole durata del processo. Diritto penale contemporaneo - Rivista trimestrale, 2013, n. 3, p. 18 ss.

VIGONI, Daniela. Ancora una riforma del giudizio abbreviato: l'inammissibilità per i delitti puniti con l'ergastolo. Diritto penale e processo, 2019, p. 918 ss.

ZAPPULLA, Angelo. Le deroghe al rito ordinario nelle varie fasi del procedimento. In: ZAPPALÀ, Enzo (a cura di), La giurisdizione specializzata nella giustizia penale minorile. $3^{\mathrm{a}}$ ed., Torino: Giappichelli, 2019, p. 93 ss.

\section{Additional information and author's declarations (scientific integrity)}

Conflict of interest declaration: the author confirms that there are no conflicts of interest in conducting this research and writing this article.

Declaration of authorship: all and only researchers who comply the authorship requirements of this article are listed as authors; all coauthors are fully responsible for this work in its entirety.

Declaration of originality: the author assures that the text here published has not been previously published in any other resource and that future republication will only take place with the express indication of the reference of this original publication; he also attests that there is no third party plagiarism or self-plagiarism. 
Dados do processo editorial

(http://www.ibraspp.com.br/revista/index.php/RBDPP/about/editorialPolicies)

- Recebido em: 04/08/2020

Equipe editorial envolvida

- Controle preliminar e verificação de plágio:

- Editor-chefe: 1 (VGV)

07/08/2020

- Avaliação 1: 26/08/2020

- Editor-associada: 1 (BC)

- Avaliação 2: 03/09/2020

- Revisores: 3

- Avaliação 3: 07/09/2020

- Decisão editorial preliminar: 20/09/2020

- Retorno rodada de correções: 30/09/2020

- Decisão editorial final: 01/10/2020

\section{COMO CITAR ESTE ARTIGO:}

PASCUCCI, Nicola. Durata ed efficienza dei procedimenti penali italiani. Riflessioni e proposte alla luce delle risultanze numeriche. Revista Brasileira de Direito Processual Penal, Porto Alegre, vol. 6, n. 3, p. 1445-1502, set./dez. 2020. https://doi.org/10.22197/rbdpp.v6i3.438

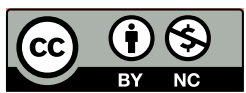

Esta obra está licenciada com uma Licença Creative Commons Atribuição-NãoComercial 4.0 Internacional. 